Volume (3) No. (4) 2020

النمذجة السببية للعلاقات بين جودة الحياة والخوف من كورونا (COVID-19) والصمود النفسي والخوف الاجتماعي والتدين والعوامل الخمسة الكبرى للشخصية في المجتمع العربي

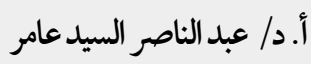


النمذجة السبية للعلاقات بين جودة الحياة والخوف من كورونا (COVID-19) و الصمود النفسي والخوف الاجتحاعي والتدين والعوامل الخمسة الكبرى للشخصية في المجتمع العربي

$$
\text { أ.د/ عبد الناصر السيد عامر }
$$

استاذ القياس والاحصاء النفسي - كلية التربية- جامعة قناة السويس، مصر، adr.abdenasser@yahoo.com

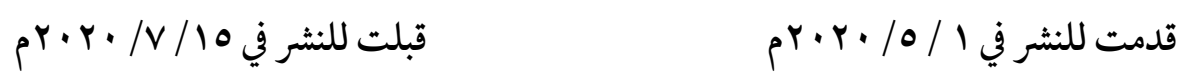

المستخلص: هدفت الدراسة إلى تحديدمستوي جودة الحياة والخوف من جائحة كورونا (COVID-19) و الصمود النفسي وكذلك التحقق من النموذج السبي بين جودة الحياة، الخوف من كورنا، الصمود النفي،، التدين، القلق الاجتماعي، والعو امل الخمسة للشخصية لعينة من المجتمع العربي. المشاركون 538 فرداً وُزعت حسب الجنس 123(22.9\%) ذكر و415 (77.1\%) بمتوسط عمر 27.186 عام و انحر اف معياري 9.816؛ الجنسية 442 (82.2\%) مصرية و96(17.8) جنسيات عربية فلسطينية (61)، سعودية (11)، أردنية (7)، و الباقية سورية، يمنية، تونسية وغيرها. وأستخدمت مقاييس مختصرة لجودة

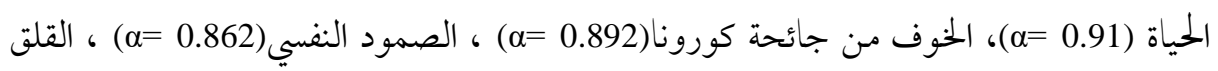

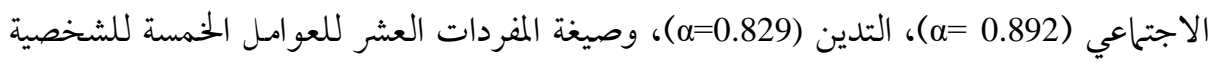
(Rammstedt \& John بيرسون، وتحليل المسار . و كشفت النتائج تو افر مظاهر جودة الحياة والصمود النفيي بدرجة كبيرة بينما

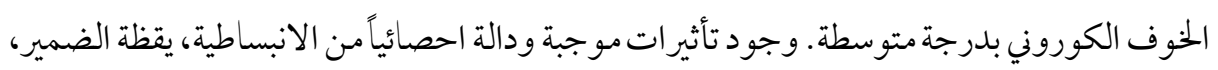
المقبولية، التدين، والصمود النفسي علن جودة الحياة بينما تأثير سالب من القلق الاجتماعي، وتأثيرات موجبة ودالة من القلق الاجتماعي والعصابية والتدين علن الخوف الكوروني، تأثيرات سالبة من الانبساطية والمقبولية ويقظة الضمير للقلق الاجتماعي بينما تأثيرات موجبة من العصابية والانفتاحية؛ وتأثيرات موجبة من الانبساطية ويقظة الضمير والمقبولية والتدين علن الصمود النفسي. وتمت مناقشة أهمية ومحددات وتوصيات الدراسة. 
Volume (3) No. (4) 2020

الكلمات الدلالية: جودة الحياة، الخوف من كورونا، الصمود النفسي، العوامل الخمسة الكبرن للشخصية، التدين. 


\title{
Causal modeling for relationships among quality of life, fear of COVID- 19, psychological resilience, social anxiety, religiosity, and the big five factors of personality in the Arabian community
}

\author{
Prof. Dr. abdenasser Alsayed Amer \\ Professor of measurement and Psychological statistics, College of Education, Suez \\ Canal University, Egypt, adr.abdenasser@yahoo.com
}

\begin{abstract}
The current study aimed to determine the levels of quality of life, fear of Covid-19, and psychological resilience and also examine the causal model among quality of life, Fear of COVID-19, psychological resilience, social anxiety, big five factors of personality, and religiosity in Arabian community. Survey and correlation study was conducted to 538 participant, age $(\mathrm{M}=27.19, \mathrm{SD}=9.82)$, nationality (442 Egyptian, 96 Arabian countries). A brief versions of scales were used, quality of life $(\alpha=0.91)$, fear of COVID-19 $(\alpha=0.892)$, psychological resilience $(\alpha=0.862)$, social anxiety ( $\alpha=0.892$ ), religiosity ( $\alpha=0.829$ ), and 10 item version of big five of personality (Rammstedt \& John, 2007). Descriptive statistics, Pearson correlation, and path analysis by LISREL were conducted to analyze the data. Results revealed medium levels of COVID-19 while high levels of quality of life and resilience. Extraversion, agreeableness, conscientiousness, resilience, and religiosity have significant direct positive effects on the quality of life while social anxiety has negative effect. Social anxiety, neuroticism, and religiosity have Significant Positive effects on the fear of COVID-19. Extraversion, agreeableness, conscientiousness have significant negative effects on the social anxiety while neuroticism and openness have positive effects. Extraversion, agreeableness, conscientiousness, and religiosity have significant direct positive effects on resilience. The importance, limitations, and recommendations of the study were discussed.
\end{abstract}

Key words: quality of life, fear of covid-19, Psychological resilience, Big five factor of personality, and religiosity. 
Volume (3) No. (4) 2020

http://dx.doi.org/10.29009/ijres.3.4.10 
ظهر فيروس كورونا المستجد المعروف بكوفيد COVID-19 في مدينة يووهان عاصمة مقاطعة هوبي الصينية في ديسمبر 9 ا • بم وما لبث أن انتشر إلى معظم دول العالم في بداية عام 2020 وتحول إلى

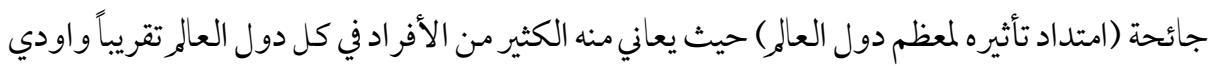
بحياة أكثر من · r ألف شخص تقريبا و اصيب به ما يقترب من سبعة مليون شخص لحظة كتابة تقرير البحث، ومن عواقبه أحداث حالة من الهلع والخوف والقلق بين كل افراد الشعوب وتغير انهاط الحياة والعلاقات إلاجتماعية. والخوف الكوروني حالة انفعالية مصحوبة بالتوتر والرعب والذعر جراء جائحة كورونا التي يمر بها المجتمع، وقد أحدث هذا الخوف اضطر ابات نفسية انعكست علن كل

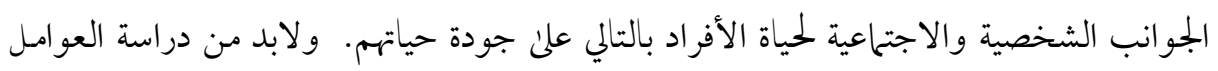
النفسية والشخصية التي تؤثر على احداث او مقاومة هذا الخوف وجودة حياة الأفراد في ظل هذه الجائحة الكورونية. وتعتبر سمات الشخصية والصمود النفسي والقلق الاجتماعي من أهم العوامل المؤثرة علن جودة الحياة والخوف من كورونا بالإضافة إلى عامل التدين والتقرب إلى الله حيث يمثل أهم

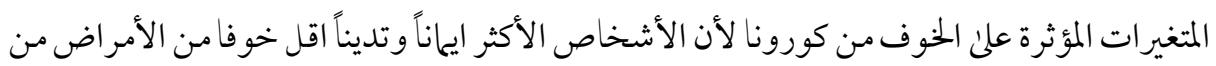
أقرانهم الأقل تديناً نتيجة اعتقاده بأن المرض هو منحة من الله وابتلاء لابد أن نرضي به. و تعكس جودة الحياة ادر اكات الفرد بسعادته، وحزنه، وفرحه، ورضاه عن وضعه الاجتماعي والنفيي والعائلي والصحي، وتمتد جودة الحياة لتشمل السعادة والرضا عن الحياة كالصحة النفسية

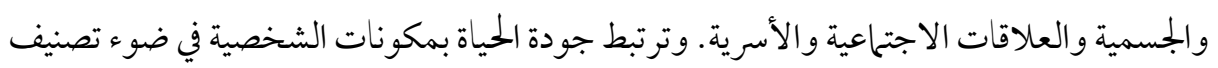
العوامل الخمسة الكبرىن 1993)، 1987; Goldberg،Costa \& McCrae( المكون من عامل الانبساطية وتعكس الحاجة للمشاركة الاجتماعية والبهجة والسرور والتفاؤل، وعامل المقبولية أو هول الطيبة وتعكس مظاهر الثقة والاهتحام والتعاون والدفء ومشاركة الأخرين والتعاطف معهم، عامل يقظة الضمير وتعكس مظاهر تحمل المسئولية والاتقان والعمل الجلاد والالتزام بالقواعد، عامل 
العصابية ويرتبط بالاستقرار الانفعلي والقلق والتوتر والحزن، عامل الانفتاحية على الخبرة ويعكس

$$
\text { الابداع وحب الاستطلاع وتقبل آراء الاخرين والتحرر من القيود. }
$$

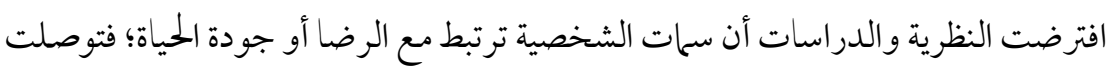
الدراسات إلى علاقة ارتباطية وتأثير موجب من الانبساطية والمقبولية ويقظة الضمير إلى جودة الحياة،

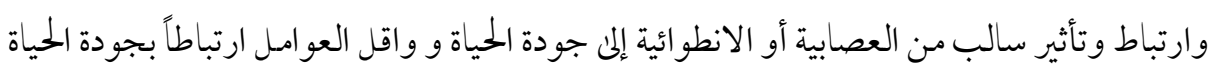

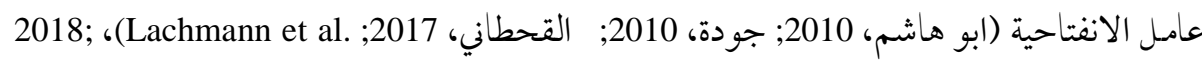
‘Gomez-Fraguela ، Lueng، Villar، 2017; Remero، \& Jopp، Congard، Dupuis،Pocent (2009 ،. كما ارتبطت الانبساطية ارتباطاً سالباً بالاضطر ابات العصابية مثل الخوف والقلقونeng) ، . 2012)، \& Xu، Miao، Zuo، Zhang، Li، Li،Zhang ويعتبر الصمود النفسي من العمليات النفسية التي يستخدمها الفرد في مواجهة المخاطر و المصائب المختلفة التي يتعرض لها في حياته الاجتماعية والاقتصادية والنفسية وغيرها لإحداث نوعا من التوافق الشخصي وهي من أفضل الآليات النفسية التي تساعد الفرد على مو اجهة عواقب جائحة كورونا. التحليل المنطقي يقول كلما زادت درجة المقاومة أو الصمود النفسي تزداد قدرة الشخص على لئ سلى مو اجهة التحديات الناتجة عن جائحة كورونا وتعمل كحاجز يحول بين الفردو الإصابة بالأمراض النفسية والجسمية المرتبطة بالضغوط، فالفرد ذو الشخصية الصلبة يميل للتفاؤل والتعامل بصورة جادة وفعالة مع الضغوط لذلك التكيف مع المو اقف الضاغطة. وتوجد علاقة ارتباطية وتأثير مباشر موجب من الصمود النفيي إلى جودة الحياة(الخشن، 2018; صباح والشجسري2017; عبد الله، 2020; ابليش، 2016; وارتباط وتأثير 2017)، Cao \& Ren، Zhao، 2017; Zhang، Liston \& Adamis،McCarthy موجب من الانبساطية والمقبولية ويقظة الضمير والانفتاحية إلى الصمود، بينما ارتباط سالبة مع ، 2006; Ercan، \& Stein، Cohan،Campbell-Sills 2014; العصابية(درويش، 2016; باعلي، إلى Fayombo (2010) مaneko، Oshio،2017; Nakaya ان اكثر العو امل اسهاماً في تفسير الصمود النفسي هي يقظة الضمير، العصابية (تأثير سالب)، المقبولية، 
الانفتاجية علن التوالي، بينما لرتسهم الانبساطية في تفسير الصمود. وباستخدام ما وراء التحليل توصل

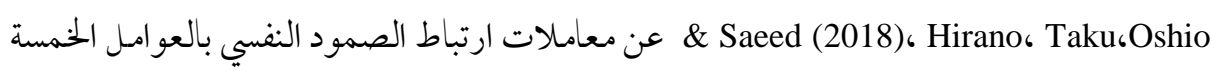
للشخصية العصابية (0.45-)، يقظة الضمير (0.42)، الانبساطية (0.42)، الانفتاحية (0.34)، والمقبولية

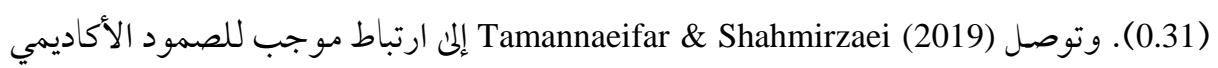
مع الضمير (0.53)، مع الانبساطية (0.35) وتوصن (20.45)، مع المقبولية (0.28)، ومع الانفتاحية (0.10)؛ بينما كان الان

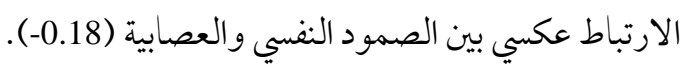

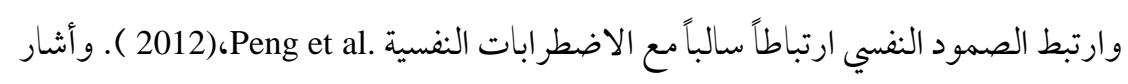
الألم \& Dugas (2009) ، Vincent،Guinn

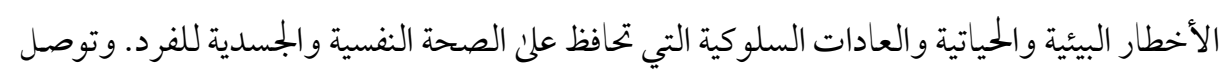
Maltby \& Dale (2019)،Ovaska-Stafford

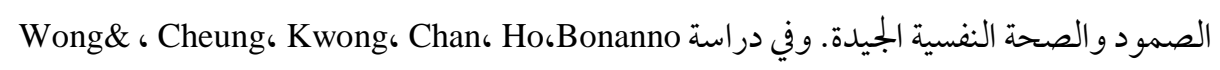

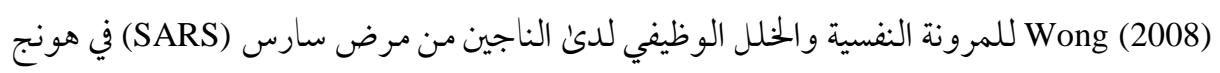
كونج، كان الأفراد ذوئ المستوئ العالي من الصمود النفسي يتمتعون بدعم اجتماعي أكبر هم أقل قلقاً متعلقًاً بالسارس، كان الافراد وترتبط جودة الحياة بمتغير في غاية الأهمية وهو التدين بمعني التمسك بأداء الفرائض والسنة

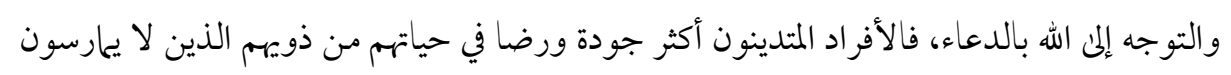

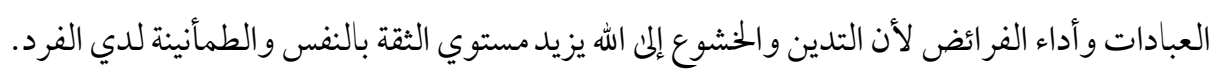

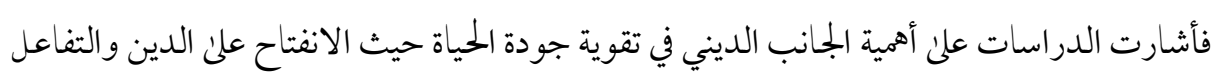

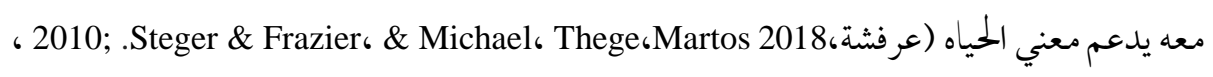

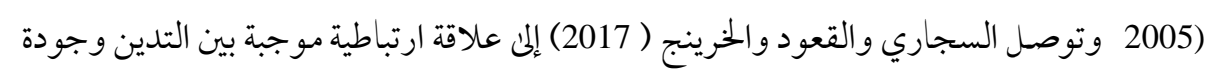

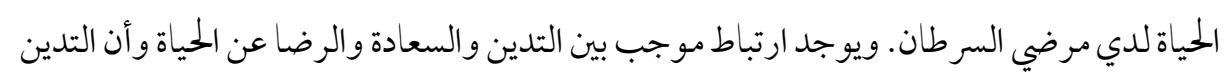

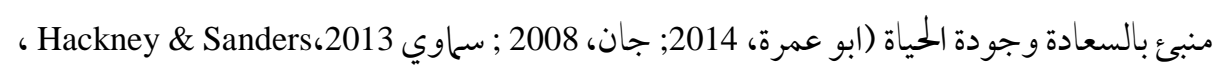


(1999; Rule،2003; Kennedy والسعادة توصل \& Haring (1985)، Okun، Stock،Witter ان العلاقة بينها 0.17. وفي مراجعة ، Reinert، Koenig، Kimura،Abdala تحليلة لـ 12 دراسة في الفترة من 2004 حتى 2012 توصل Horton (2015) إلى أن 75\% من الدراسات وجدت علاقة ارتباطية موجبة بين جودة الحياة والتدين بينما 25\% توصلت إلى لا ارتباط. وممارسة المعتقدات الدينية تريح الانسان المتوتر والعصبي، وباعتبار القلق يتضمن مظهر الخوف راجع McCullough،Koenig ، Larson. (2001) \& ع ع الي 76 دراسة تناولت العلاقة بين التضمين الديني والقلق او الخوف قبل عام 2000 منها 69 دراسة ارتباطية، 35 دراسة توصلت إلى الأفراد الاكثر تديناً اقل خوفاً وقلقاً، و 24 دراسة ارتباطية توصلت إلى لأل علاقة بينها و10 دراسات توصلت إلى الأفراد الاكثر تديناً اكثر قلقاً. . وكشفت دراسة Brown،Lee عن وجود علاقة ارتباطية مو جبة بين التدين و الصمود النفسي لدني

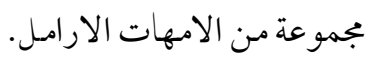
ومن المتغيرات المهمة المؤثرة علن الخوف من كورونا وجودة الحياة، القلق الاجتماعي وهو الخوف والتوتر من التفاعل مع الاخرين حيث يعتبر من اقوي الانفعالات المؤثرة في حياتنا، ويعد القلق الاجتماعي من الاضطر ابات النفسية، وتتبدئ خطورة القلق الاجتماعي في أنه يؤثر سلباً في جودة الحياة؛ فتوصلت الدراسات إلى ان المستويات المرتفعة للقلق الاجتحاعي تؤدي إلى مستويات منخفضة لجودة

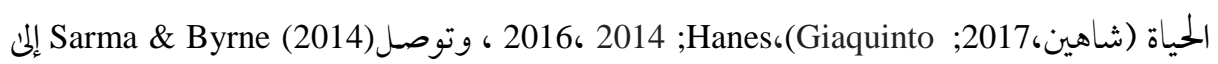
ان القلق العام منبئ سالب بكل مظاهر جودة الحياة الاجتحاعية والنفسية و الصحية و البيئة لدي عينة من المرضي. ويرتبط القلق الاجتماعي ارتباطاً موجباً مع العصابية وسالب مع الانبساطية ويقظة الضمير والمقبولية والانفتاحية 2011)، 2008; Roselline \& Brown،(Morris \& Gilliland . وتوصل Abbasi-Asi \& Naderi الانبساطية والمقبولية تسهم اسهاماً سالباً في حين ان يقظة الضمير والانفتاحية غير منبئة لعينة من

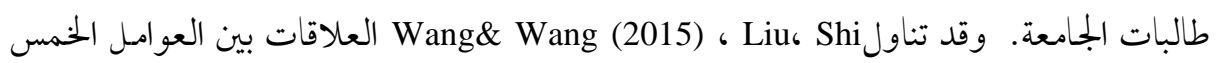


الكبرى للشخصية وأعراض القلق بين طلاب الطب، واستكشاف الدور الوسيط للصمود النفيي في هذه العلاقة وتوصلت الدراسة إلى ارتباط كلاً من مكونات المقبولية والضمير والانفتاح سلبًا بالقلق بينما موجباً مع العصابية. ولعب الصمود النفسي كوسيط للعلاقات بين المقبولية، الضمير، الانفتاحية وأعراض القلق. وتوصل (2016) Yngve إلى ارتباط وتأثير مباشر سالب من الصمود إلى القلق الاجتماعي. كما توصلت دراسة (2019) Ko \& Chang إلى تأثير مباشر من الصمود النفيي إلى القلق الاجتماعي. ولكن الاشكالية في هذه الحالة هل الحوف من جائحة كورونا ناتج أم سبب لجودة الحياة؟، بمعني كلما كان الفرد أكثر سعادة أو جودة في حياته يكون اقل خوفاً وفي هذه الحالة فان الخوف ناتج، ولكن الدراسات السابقة والتحليل السيكولوجي يقول أن الخوف يسبب خلل في جودة الحياة وايضاً كلما الفردصامداً نفسياً كلما كان أكثر قدرة علن مواجهة الخوف و و القلق، ويمكن القبول بالتحليل

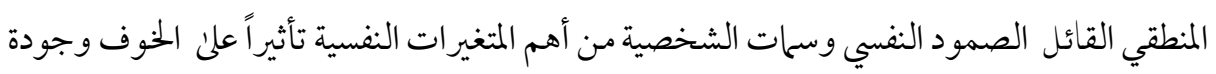
الحياة وكل هذه الاطروحات ما تحاول الدراسة الوصول إلى اجابه له. ويبدو أن الدراسات السابقة تؤكد علن أن جودة الحياة ناتج نهائي يؤثر عليه مكونات الشخصية والانفعالات والصمود و التدين.

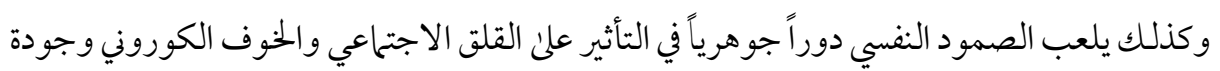
الحياة. وفي ضوء العرض السابق يمكن طرح أسئلة الدراسة كالتالي: - ما مستوي جودة الحياة في ضوء جائحة كورونا لعينة من المجتمع العربي؟

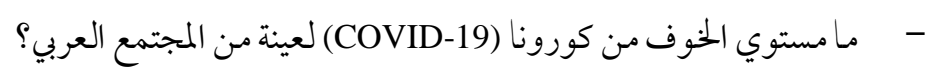
- - ما هي مستوي الصمود النفسي لدي عينة من المجتمع العربي؟ - ما طبيعة العلاقات الارتباطية بين جودة الحياة والخوف من كورونا، الصمود النفسي،

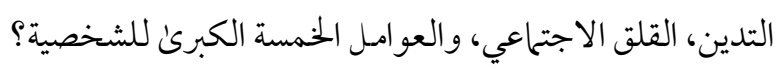


- ماهي طبيعة التأثيرات السببية بين جودة الحياة، الخوف من جائحة كورونا، الصمود النفسي، القلق الاجتماعي، التدين، والعوامل الخمسة الكبرىن للشخصية لدي عينة من المجتمع لِين

$$
\text { النموذج السببي المقترح }
$$

في ضوء الدراسات السابقة والتحليل النظري يمكن اشتقاق النموذج السببي وفيه اعتبرنا جودة الحياة متغير داخلي ناتج نهائي بينما الصمود النفسي والخوف الكوروني والقلق الاجتماعي متغيرات وسيطية وعو امل الشخصية والتدين متغيرات خارجية مستقلة.

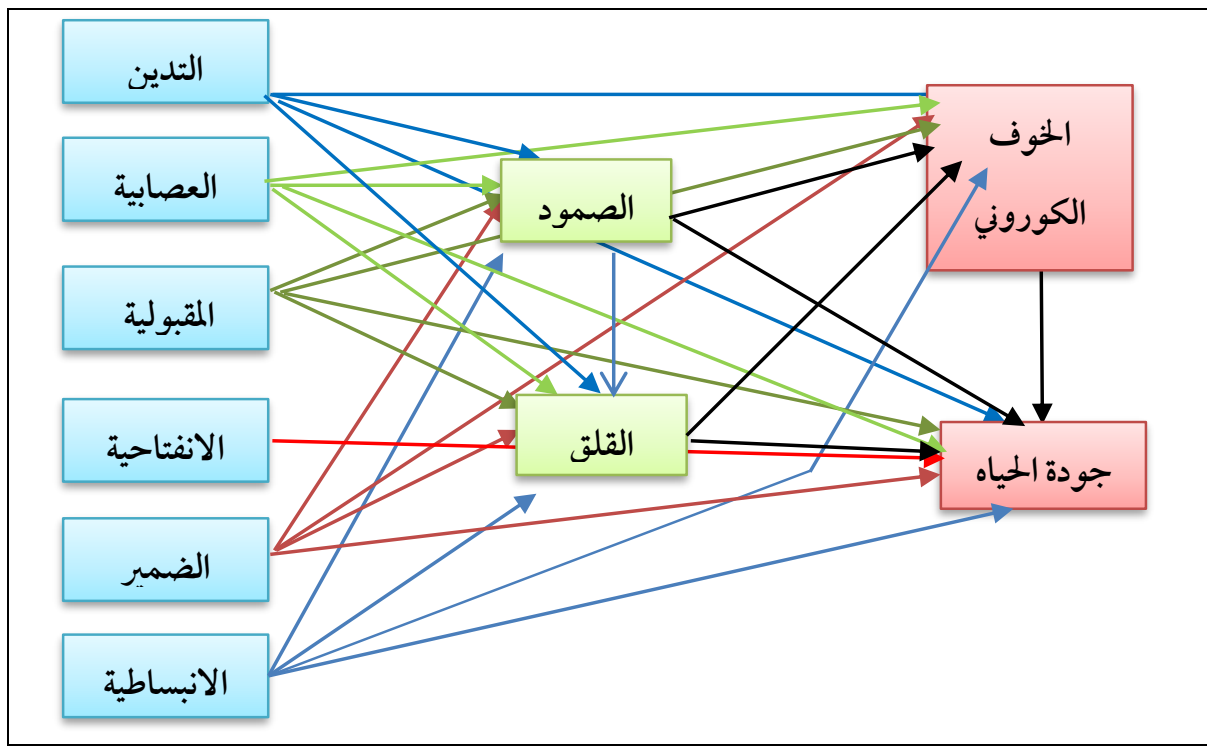

$$
\text { الشكل(1): النموذج السببي المفترض بين متغيرات الدراسة. }
$$

وعليه فان الهدف الرئيسي من الدراسة تحديد دور الذي تلعبه العوامل الخمسة الكبرى للشخصية، والصمود النفسي، التدين، والقلق الاجتماعي، علن كلاً من جودة الحياة والخوف من كورونا في حالة إذا ما اعتبرنا أن الصمود النفسي والخوف الاجتماعي متغيرات وسيطة بينما عو امل الشخصية الخمسة والتدين متغيرات خارجية (مستقلة). وتسعي الدراسة ايضاً إلى تحديد مستوي أو درجة الخوف 
من جائحة كورونا وجودة الحياة والصمود النفسي لدي عينة من الأفراد في المجتمع العربي في ظل هذه الظروف القاسية التي يمر بها العالم. الطريقة والاجراءات وتتضمن النواحي المنهجية الآتية:

المنهج: اعتمدت الدراسة على تصميم الدراسات المستعرضة متضمنة المنهج الوصفي من خلال تطبيق مقاييس علن عينة كبيرة من الأفر ادلتحديد مستويات الخوف من كوروناوجودة الحياة والصمود، كحا اعتمدت علن المنهج الارتباطي لجمع بيانات للتحقق من النموذج السببي المفترض للتأثيرات السببية بين المتغيرات.

المثاركون: تم الحصول على عينة متاحة علن الانترنت من خلال طرح مقاييس الدراسة على لم صيغة Google form وتم ارساها إلى العديدمن الأفراد و كذلك التنبيه عليهم لإرساها إلى اخرين (عينة كرة الثلج) حيث يكون التطبيق إلكترونياً علن التليفون من خلال لينك مرسل له كالاتي: https://docs.google.com/forms/d/1q51lkWzsGfDtlZt-SUjHPGc7-0R46hl4voJtE2CeGOM/edit بالتالي مجتمع العينة هو مستخدمي التليفونات الذكية أو الانترنت وهي بجتمع غير محدد لدراسة ظاهرة كونية عالمية وهي جائحة كورونا. وبلغ المشاركون 538 فرداً تنوعت حسب الجنس إلى

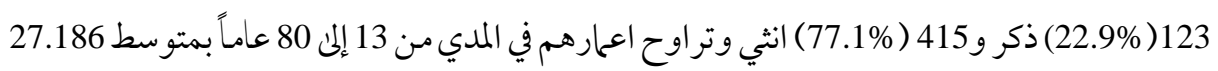
عام وبانحر اف معياري 9.816، وتراوحت أعمار 77.890\% من المشاركين في المدي من 19 1واماً إلى 32عاماً. وحسب الجنسية 442 (82.2\%) مصري و96(17.8) جنسيات عربية تنوعت إلى فلسطيني (61) وسعودي (11) وأردني (7) والباقي سوري، يمني، تونسي وغيرها. وحسب المؤهل التعليمي 11 (2\%) مرحلة ابتدائية و^ا (3.3\%) مر حلة اعدادية و 21 (3.9\%) ثانوية و400 (74.3\%) جامعي، 64 (11.9\%) دراسات عليا و23(4.3\%) حاملي الدكتوراة والماجستير. وفي ضوء المهنة كانت 200 (37.1\%) طالب، 146 (27.1\%) مدرس، 54(10\%) موظف، 37 ( 6.9\%) لا يعمل، $28(5.2)$ اعمال خاصة، 18(3.3\%) دكتور، 11(2\%) عامل وتنوعت بقية وظائف العينة من تمريض، محاسب، مهندس، وغيرها. 
القياسات: نظر ألتعدد مقاييس الدراسة تم الاعتماد علن صيغ ختصرة للمقاييس كالتالي: مقياس جودة الحياة: تم الاستعانة بـ 15 مفردات من مقياس منظمة الصحة العالمية لقياس جودة الحياة (1995) وتم اختيار هذه المفردات بـا يتناسب ومواقف الحياة للتعامل مع جائحة كورونا متضمن العلاقات الاجتماعية، الأسرية، الوظيفية، الصحة العامة، النفسية، المسكن، الرضاعن النفس. وصيغت المفردات في تساؤلات مثل إلى أي درجة تشعر بالسعادة في حياتك؟، إلى أي درجة أنت راضي عن نفسك؟، هل تشعر بالطمأنينة وراحة البال؟، وتم تصحيحها في ضوء مقياس ليكرت الخحاسي و أعيدت تصحيح المفردة "ما درجة المشاعر السلبية لديك (احباط، اكتئاب، قلق) لأنها عبارة سلبية. وتم تقدير معامل الثبات الفا للمقياس وبلغ 0.905 وتراوحت قيمة معامل ثبات الفا للمقياس بعد استبعاد المفردة من 0.893 الي 0.905 ومعامل الارتباط المصحح من 0.434 إلى 0.755. وتم التحقق من Direct Oblimin صدق البناء باستخدام التحليل العاملي بطريقة المكونات الاساسية والتدوير المائل وبلغت قيمة محلك كايزر ماير اولكين لاختبار مناسبة مصفوفة معاملات الارتباط للتحليل 0.926 وهي قيمة مرضية جداً ، وافرز التحليل عاملين بجذر كامن للأول 6.683 وفسر الارتباطات وتشبع عليه 12 مفردة بمعاملات تشبع من 0.415 إلى 0.840 وهي مفردات تعكس جودة الحياة الذاتية للفرد، بينما بلغ الجذر الكامن للعامل الثاني 1.047 وفسر 6.983 من تباين المصفوفة وتشبع عليه ثلاثة مفردات بمعاملات تشبع من 0.648 الي 0.783 وهي تعبر عن جودة الحياة للفرد في علاقته بالأخرين (هل تشعر بالرضا في حياتك العائلية؟). الملاحظ أن معاملات التشبع مرتفعة فزادت في

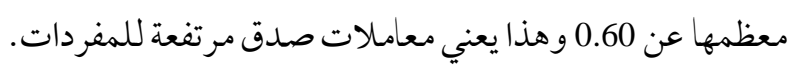
مقياس العوامل الخمسة الكبرى للشخصية: الاستعانة بالصيغة عشر مفردات المختصرة وفيها

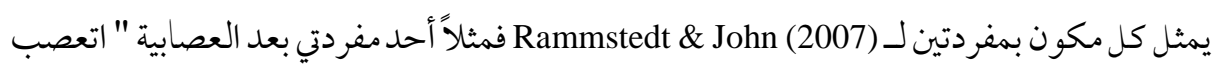
بسرعة" وصصحح في ضوء مقياس ليكرت الخحاسي. بناء مقياس الخوف من جائحة كورونا: المرحلة الأولي تم الاطلاع علن العديد من مقاييس

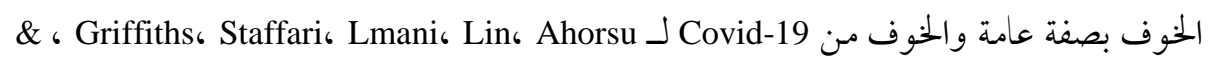


أ.د/ عبد الناصر السيد عامر المجلد (3) العدد (4) 2020م

المكون سبعة مفردات حيث اهتمو ا بمظاهر الخوف الشخصي ولم يتناولوا المظاهر Pakpour (2020) السلوكية المرتبطة بالحوف. المرحلة الثانية تم اجراء مقابلات مع بعض طلاب الدراسات العليا في

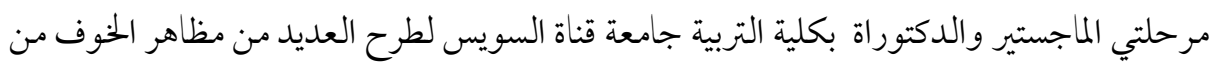
كوروناوحدث أثناء النقاش هل نطلق عليه الخوف او القلق او ما يطلق عليه في التراث حساسية القلق anxiety sensitivity

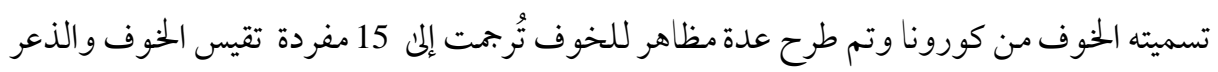
وتجنب الخروج من المنزل تجنباً للإصابة مثل" اشعر بالذعر من سماع الاخبار عن وفيات فيروس كورس كورونا"، "انا اخاف من الاصابة بكورونا". و كذلك يتضمن بعض مظاهر السلوكية مثل التجنب من الاخرين مثل "أتجنب زيارة اقاربي خوفا من كورونا". المرحلة الثالثة عُرضت المفردات 15 علن ثلاثة متخصصين في علم النفس واتفقوا على استبعاد مفردتين بها تكرار ببعض العبارات بالتالي تضمن المقياس 13 مفردة وصُححت في ضوء مقياس ليكرت الخحاسي. وقُدر ثبات المعامل الفا للمقياس حيث بلغ 0.885 ولكن توجد اشكالية لمفردة "أنا غير مهتم بالحديث عن كورونا" في المقياس حيث زادت قيمة المعامل الفا للمقياس بعد حذفها 0.892 وبحذفها أصبح ثبات المقياس 0.892 وعليه أصبح 12مفردة، وتراوحت الفا للمقياس بعد حذف المفردة من 0.867 إلى 0.892، بينما بلغت قيم معامل الارتباط المصحح من 0.446 إلى 0.775 وهذا يدل على التجانسية العالية للمفردات لقياس الخوف من كورونا. ولتحقق من الصدق البنائي أجريت طريقة المكونات الاساسية والتدوي المائل Direct Oblimin بلغ الجذر الكامن للعامل الأول 4.265 ولثثاني 3.051 (بعد التدوير)، بينما فسر العامل الأول 35.545 و الثاني 25.421 من تباين مصفوفة الارتباط وبلغ التباين المفسر الاجمالي 60.966، اي أن مفردات المقياس استخلصت هذه النسبة العالية من البناء التحتي للخوف من كورونا. وتشبع بالعامل الأول 7 مفردات تمثل الخوف من مزاولة الممارسات اليومية والتعامل مع الاخرين جراء جائحة كورونا 
(الخروج، المصافحة، ملامسة الوجه، الخوف من الاخرين) وتراوحت معاملات التشبع من 0.599 إلى 0.846، بينما تشبع بالعامل الثاني 5 مفردات تمثل الخوف الشخصي (الذعر، الرعب، الاحلام المرعبة، الشك من اعر اض كورونا) وتراوحت معاملات التشبع من 0.651 المى 0.817 مما يدل على معاملات

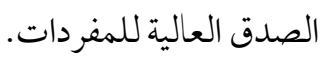

مقياس الصمود النفسي: يشير الصمود النفسي إلى قدرة الفرد علن استعادة توازنه بعد التعرض للمحن والصدمات المضطربة التي تو اجه، وفي إطار بناء صيغ خختصرة من المقياس تم الاستعانة بعشرة مفردات من مقياس Conner \& Davidson بما يتناسب مع مو اجهة جائحة كورونا مثل" لدي الاصرار والعزيمة علن مو اجهة أي صعوبات في حياتي في ظل جائحة كورونا."، " أستطيع مو اجهة

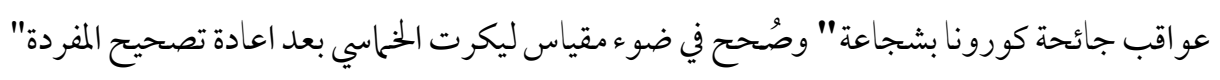
أخشى من مواجهة جائحة كورونا والتكيف معها" ". بلغ معامل الثبات الفا للمقياس 0.820

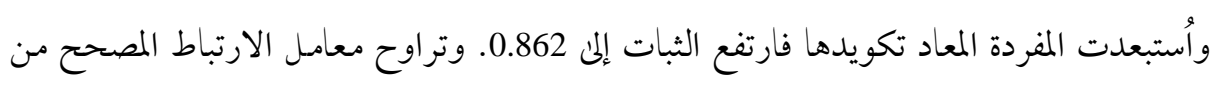
0.376 إلى 0.753. وتم التحقق من الصدق البنائي بإجراء طريقة المكونات الاساسية والتدوير المائل ميث بلغت قيمة محك ماير كايزر اولكين 0.897 وهي مناسبة جداً. وافرز التحليل عامل عام بجذر كامن 4.362 وفسر 48.464 من تباين مصفوفة الارتباط وتراوحت التشبعات من فئ 0.468 إلى 0.836 مما يؤكد على صدق البناء الصمود النفسي. مقياس القلق الاجتماعي: القلق الاجتماعي هو الخوف الشديد او التوتر جراء مواجهة شخص أو أكثر في المواقف الاجتماعية المختلفة. وبالاطلاع علن تراث قياس الخوف الاجتماعي مثل Caballo)، ، \& B Bond 1989)، Beidel، Stanly، 2013; Turner، \& Nobre، Arias، Irurtia،Salazar المقياس من عشرة مفردات تضمنت القلق او الحرج او الارتباك من التفاعل الاجتماعي مع الاخرين

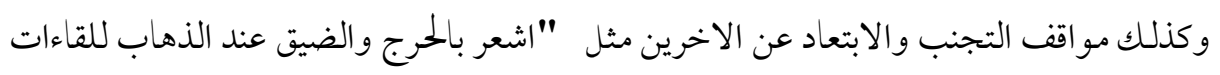

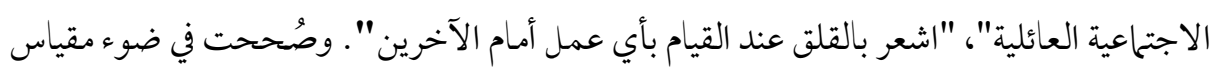
ليكرت الخماسي. وقُدر ثبات الاتساق الداخلي للمعامل الفا حيث بلغت قيمته 0.892 وتراوح معامل 
الارتباط المصحح من 0.492 إلى 0.726 مما يشير إلى الاتساق الدخلي المناسب بين المفردة والدرجة الكلية Deعد حذف درجة المفردة. وقُدر صدق البناء باستخدام المكونات الاساسية والتدوير المائل Direct Oblimin العاملي بدرجة كبيرة جداً. و أفرز التحليل عاملين بلغ الجذر الكامن للأول 5.16، وللثاني 1.024 وفسرا 51.638\% و 10.244\% علن التو الي بإجمالي 61.882\% من تباين مصفوفة معامل الارتباط حيث تشبعت كل المفردات علن العامل الأول قبل التدوير وبعد التدوير تشبع بالعامل الأول خمسة مفردات تمثل تجنب المو اقف الاجتماعية والاختلاط مع الاخرين، بينما تشبع بالعامل الثاني خمسة مفردات تمثل الضيق والحرج من المشاركة في المواقف الاجتماعية وزادت تشبعات كل المفردات عن 0.639. مقياس التدين Religiosity: تم إعداد مقياس التدين من واقع ممارستنا للفر ائض والشعائر اليومية ومدي التزام الفرد بأدائها وتكون المقياس من امفردات تمثثل ممارسات دينية مثل "احرص علن أداء الصلوات الخمس في اوقاتها". "اقرأ القرآن باستمرار" "أصلي علن الرسول عليه الصلاة و السلام باستمر ار"، "استمع واقرا ألأحاديث و السيرة النبوية باستمرار". تم تصحيح المقياس في ضوء البدائل نعم (2) وإلى حدا ما (1)، ولا (0). وقُدر معامل الفا لثبات الاتساق الداخلي ويلغت قيمته 0.829 وتراوحت قيمة معامل الارتباط المصحح من 0.406 إلى 0.621. وقُدر الصدق البنائي باستخدام طريقة المكونات الرئيسة والتدوير المائل وبلغت قيمة المعامل ماير كايزر اولكين 0.881 وافرز التحليل عاملين بجذر كامن 4.14 و 1.262 علن التو الي وفسرا 41.41\% و و 12.622 من تباين المصفوفة علن التوالي (بعد التدوير) وقبل التدوير تشبعت كل المفردات بالعامل الأول. بعد التدوير تشبع بالعامل الأول

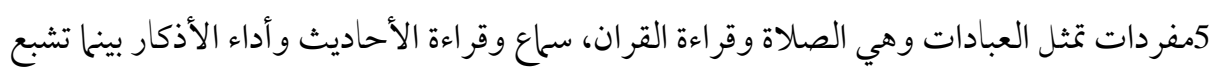
5 مفردات بالعامل الثاني تمثل التوكل علئ الله، الصلاة علن رسول الله، الدعاء، و الطمأنينة والخشوع.

تم جمع البيانات الكترونياً من خلال لينك تم ارساله إلى طلاب الجامعة وكذلكالأفر اد العاديين من المجتمع في بداية شهر ابريل واستغرق التطبيق حوالي ثلاثة اسابيع وتم التنبيه علن الأفراد ان هذه 
المقاييس لقياس هذه المفاهيم في ظل جائحة كورونا. وتم تحويل ملف بيانات الاستبيانات إلى ملف Excel ثم تحويله إلى ملف SPSS وتكويد المتغيرات التصنيفية مثل الجنس والوظيفة وغيرها. تم اجراء جمع قيم مفردات كل مقياس علن حدة. وتم التحقق من النماذج السبية في ضوء المتغيرات المقاسة باستخدام تحليل المسار للكشف عن التأثيرات السبية التفصيلية بين متغيرات الدراسة.

\section{التحليل الاحصائي}

حُللت البيانات باستخدام برنامج (23) SPSS لإجراء التحليلات الاحصائية الوصفي، معامل ارتباط بيرسون. ويرنامج LISREl للتحقق من النموذج السببي المفترض باستخدام تحليل المسار بين المتغيرات المقاسة في اطار نمذجة المعادلة البنائية وتم الاستعانة بمؤشرات المطابقة RMSEA (قيمتها CFI و CFI و (قيمتها 0.08 فاقل) 0.95 فأكثر) واحصاء كأي تربيع وقيمة P الاحتمالية المرتبطة به (عدم الدلالة الاحصائية) (عامر، 2018). النتائج ومناقشتها السؤال الأول: ما مستوي الخوف من كورونا لدي افراد العينة؟ قُدرت المتوسطات والانحر افات المعيارية وكذلك التفرطح والالتو اء للتحقق من الاعتدالية للبيانات: الجدول (1): المتوسطات والانحرافات المعيارية، الالتواء، التفرطح لمفردات الخوف من كورونا(N=538).

\begin{tabular}{|c|c|c|c|c|}
\hline 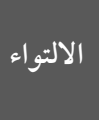 & التفرطح & الالنحراف & 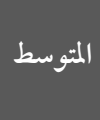 & 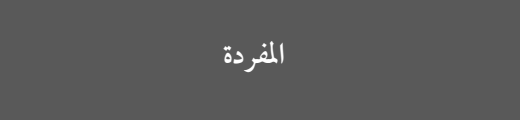 \\
\hline-.120 & -1.11 & 1.323 & 3.130 & اتجنب الخروج من المنزل حتي لا اقابل احد \\
\hline .140 & -1.28 & 43461 & 2.838 & اتجنب الصلاة في جماعة خوفاً من ملامسة الاخرين. \\
\hline-.305 & -1.05 & 1.328 & 3.361 & اتجنب زيارة اقاربي خوفا من كورونا. \\
\hline-.255 & -.884 & 1.256 & 3.329 & اخاف من الاخرين حتي لا يصيبني الفيروس. \\
\hline-.362 & -.771 & 1.242 & 3.414 & اخاف ان أسلم علن احد خوفا من ملامسة يده. \\
\hline
\end{tabular}




\begin{tabular}{|c|c|c|c|c|}
\hline 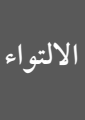 & 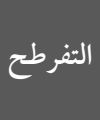 & المعياري - المراف & المتوسط & 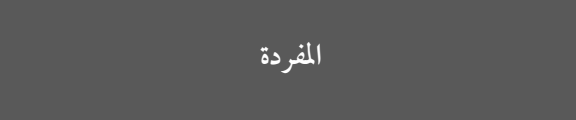 \\
\hline 0.116 & -.937 & 1.283 & 2.918 & اخاف من شراء الحاجات اليومية للشك انها تتضمن \\
\hline-.050 & -1.09 & 1.344 & 3.030 & اتجنب ملامسة وجهي خوفا للإصابة بكورونا \\
\hline .448 & -.981 & 1.361 & 2.524 & اخاف ان أصاب من كورونا لان اخاف من الموت. \\
\hline 1.781 & 2.356 & 1.086 & 1.641 & ينتابني احلام مرعبة اثناء النوم من الاصابة بكورونا. \\
\hline 0.646 & -.829 & 1.359 & 2.312 & اناعندي رعب من الاصابة بكورونا. \\
\hline 0.885 & -.327 & 1.272 & 2.169 & اشك باستمرار انني اعاني من اعراض كورونا \\
\hline-.086 & -1.18 & 1.387 & 3.087 & اشعر بالذعر من سماع الاخبار عن وفيات فيروس كورونا \\
\hline
\end{tabular}

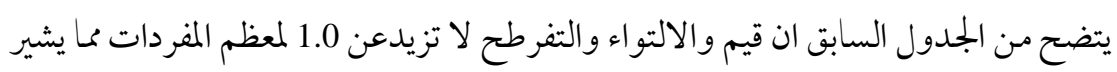

إلى توفر الاعتدالية بدرجة جيدة، وان قيم المتوسط لمعظم استجابات الأفراد تقترب من 3.0 مما يشير إلى جودة المفردات حيت تتمركز حول الاستجابة الوسيطية(عامر، 2019)، في المجمل العام فان الأفراد يعانون من الخوف من كورونا بدرجة متوسطة لمعظم المفردات ما عدا مفردات" يتتابني أحلام مرعبة أثناء النوم من الاصابة بكورونا."، " انا عندي رعب من الاصابة بكورونا." و " أشك باستمرار انني بـابي اعاني من اعراض كورونا" بدرجة قليلة. وبلغ المتوسط الكلي للمفردات المقياس 33.754 وهي تعادل 56.26\% من الدرجة الكلية (60) وهذا يشير إلى أن تو افر الخوف الكوروني بين أفراد العينة بدرجة

متوسطة.

الاجابة على السؤال الثاني: ما مستوي جودة الحياة في ظل جائحة كورونا؟، قُدرت المتوسطات والانحر افات المعيارية وكذلك التفرطح والالتو اء للتحقق الاعتدالية للبيانات: الجدول(2): المتوسطات والانحر افات المعيارية، الالتواء، والتفرطح لمفردات جودة الحياة في زمن جائحة كورونا (N=538). 
Prof. Dr. abdenasser Alsayed Amer

Volume (3) No. (4) 2020

\begin{tabular}{|c|c|c|c|c|}
\hline 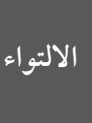 & التفرطح & الانحراف & المتوسط & 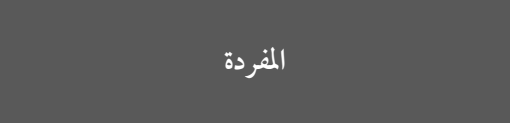 \\
\hline-.566 & 0.430 & 0.939 & 3.390 & الي اي درجة تشعر بالسعادة في حياتك؟ \\
\hline-1.09 & 1.375 & .9111 & 4.108 & الي اي درجة علاقتك جيدة مع والديك واقاربك؟ \\
\hline-.657 & -.040 & 1.0397 & 3.766 & هـل تكون علاقات جديدة؟ \\
\hline-.865 & 0.488 & 0.998 & 3.926 & هل تشعر بالرضا في حياتك العائلية؟ \\
\hline-.296 & -.270 & 1.100 & 3.214 & الي اي درجة انت مرتاح في عملك او وظيفتك؟ \\
\hline-.288 & -.097 & 1.053 & 3.152 & هـل لديك قدر من المال لتلبية احتياجاتك اليومية. \\
\hline-.054 & 0.399 & 0.930 & 3.662 & هل تشعر بالصحة الجسمانية والعافية؟ \\
\hline-.507 & -.021 & 1.034 & 3.500 & هل تشعر بالأمن والامـان في حياتك اليومية؟ \\
\hline-.507 & -.021 & 1.034 & 3.500 & هـل تشعر بالطمأنينة وراحة البال؟ \\
\hline-.962 & 0.324 & 1.065 & 3.985 & هل انت راضي عن مسكنك الذي تعيش فيه؟ \\
\hline-.560 & 0.538 & 0.907 & 3.626 & الي اي درجة قادر على تأدية اعمالك اليومية؟ \\
\hline-.564 & 0.383 & 0.959 & 3.684 & الي اي درجة انت راضي عن نفسك؟ \\
\hline-.487 & 0.101 & 0.998 & 3.346 & الي اي درجة انت مستمتع بحياتك؟ \\
\hline-.087 & -.668 & 1.142 & 2.987 & ما درجة المشاعر السلبية لديك(احباط، اكتئاب)؟ \\
\hline-.155 & 0.489 & 0.843 & 3.312 & 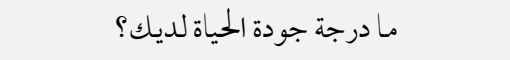 \\
\hline
\end{tabular}

يتضح من الجدول (2) ان قيم والالتواء والتفرطح لا تزيد عن 1.0 لكل المفردات ماعدا المفردة" إلى اي درجة علاقتك جيدة مع والديك واقاربك؟" مما يشير إلى توافر الاعتدالية بدرجة كبيرة، كما ان قيم المتوسط لمعظم استجابات الأفراد علن المفردات تزيد او تقترب من بما يشير إلى جودة المفردات حيت تتمركز حول الاستجابة الوسيطية. في المجمل العام فإن الأفراد يشعرون بدرجة كبيرة من جودة الحياة لمعظم المفردات حيث زادت قيمة المتوسط عن 3.50 ما عدا مفردات" إلى اي درجة انت مرتاح في عملك او وظيفتك؟ و" هل لديك قدر من المال لتلبية احتياجاتك اليومية؟" و" إلى اي درجة انت مستمتع بحياتك؟ و" ما درجة جودة الحياة لديك؟" فكانت بدرجة متوسطة. وعموماً فإن متوسط الدرجة 
الكلية لجودة الحياة 53.403 وهي تعادل 71.204\% من الدرجة الكلية (75) بالتالي تتوفر جودة الحياة بدرجة جيدة. السؤال الثالث: ما مستوي الصمود النفسي لدي افراد العينة ؟، قُدرت المتوسطات والانحرافات المعيارية، وكذلك التفرطح والالتو اء للتحقق من اعتدالية البيانات: 
Prof. Dr. abdenasser Alsayed Amer

Volume (3) No. (4) 2020

الجدول (3) : المتو سطات والانحر افات المعيارية، الالتواء، والتفرطح لمفردات الصمو د النفسي في زمن جائحة كورونا (N=538).

\begin{tabular}{|c|c|c|c|c|}
\hline الالتواء & 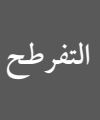 & 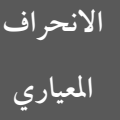 & المتوسط & 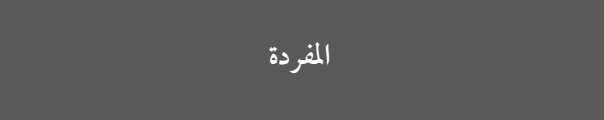 \\
\hline-1.29 & 1.366 & 0.999 & 4.173 & توجد لدي اهداف تجعلني اتسكك بالحياة بالرغم من كورونا \\
\hline 0.147 & -.811 & 1.216 & 2.786 & اخشي من مو اجهة كورونا والتكيف معها. \\
\hline-1.06 & -0.81 & 0.987 & 4.102 & انا متفائل من اجتياز مرحلة جائحة كورونا \\
\hline-1.09 & 0.686 & 1.074 & 4.013 & نستحق ان نعيش الحياة بكل ما فيها بالرغم من كورونا \\
\hline-.626 & -.236 & 1.097 & 3.736 & اسعي بكل الطرق لتحقيق هدفي في ظل كورونا \\
\hline-.804 & 0.350 & 1.032 & 3.799 & لدي القدرة علن المثابرة للتغلب علن اي مشكلة تو اجهني \\
\hline-.927 & 0.780 & 0.905 & 4.11 & اتعامل مع جائحة كورونا بموضوعية واتبع التعليمات \\
\hline-.543 & 0.742 & 0.985 & 3.890 & لديه الاصرار والعزيمة لمواجهة اي صعوبات في حياتي في \\
\hline-.474 & 0.015 & 1.0478 & 3.543 & اعتقد ان تأثيري قوي علن اسرتي في ظل كورونا \\
\hline 0.646 & -.829 & 1.0362 & 3.559 & استطيع مو اجهة عواقب جائحة كورونا بشجاعة \\
\hline
\end{tabular}

يتضح من جدول(3) يتضح ان قيم والالتواء والتفرطح لمعظم المفردات لا تذيد عن 1.0 مما يشير إلى تو افر الاعتدالية بدرجة مناسبة كما ان قيم المتوسط لكل استجابات الأفراد على المفردات تذيد عن 3.5 ما عدا المفردة" اخشي من مو اجهة كورونا والتكيف معها" وقد يرجع هذا إلن صياغتها السلبية وهذا يشير إلى توفر الصمود النفسي لدي افراد العينة بدرجة كبيرة. وبلغ المتوسط الكلي لمفردات المقياس 34.524 وهي تعادل 69.05\% من الدرجة الكلية (50) وهذا يشير إلى توفر مستوي الصمود النفيي لدي افراد العينة بدرجة كبيرة في المجتمع العربي. التحليلات الوصفية: فيها يلي عرض احصائيات وصفية للمتغيرات يتضمن المتوسط والانحراف المعياري والالتو اء والتفرطح كما في جدول (4). 


\begin{tabular}{|c|c|c|c|c|}
\hline التفرطح & 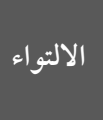 & الاندر اف & المتوسط & المتغير \\
\hline 0.456 & -.418 & 1.616 & 6.842 & الانبساطي*(2) \\
\hline-.492 & -.183 & 1.576 & 7.327 & العصابية(2) \\
\hline 1.263 & -.667 & 1.490 & 7.632 & المقبولية(2 ) \\
\hline 0.116 & -.342 & 1.619 & 6.991 & يقظة الضمير(2 ) \\
\hline-.397 & -.039 & 1.793 & 6.582 & الانفتاحية(2 ) \\
\hline-.274 & 0.255 & 8.665 & 27.660 & الخوف الاجتماعي(10) \\
\hline 2.51 & -1.283 & 3.251 & 13.052 & التدين(9) \\
\hline 1.225 & -.869 & 6.329 & 34.524 & الصمود النفسي((10) \\
\hline-.413 & 0.203 & 10.622 & 33.754 & الخوف الكوروني(12) \\
\hline 0.414 & -.571 & 9.764 & 53.403 & جودة الحياة(15 ) \\
\hline
\end{tabular}

ويتضح من الجدول ان اكثر عوامل الشخصية سيطرة المقبولية والعصابية يليها الانبساطية ثم يقظة الضمير واقلهم سيطرة الانفتاحية بينما توفر الخوف الاجتماعي بدرجة متوسطة وتوفر مستوي التدين (65.26\%) بدرجة متوسطة إلى حداً ما. السؤال الثالث: ما طبيعة العلاقات الارتباطات بين متغيرات الدراسة؟، قُدر معامل ارتباط بيرسون بين متغيرات وفيما يلي مصفوفة معامل الارتباط: 
Prof. Dr. abdenasser Alsayed Amer

Volume (3) No. (4) 2020

الجدول (5): مصفوفة الارتباط بين متغيرات الدراسة(N=238).

\begin{tabular}{|c|c|c|c|c|c|c|c|c|c|c|}
\hline 10 & 9 & 8 & 7 & 6 & 5 & 4 & 3 & 2 & 1 & المتغير \\
\hline & & & & & & & & & 1.0 & الانبساطية(1) \\
\hline & & & & & & & & 1.0 & $-.18^{* *}$ & العصابية(2) \\
\hline & & & & & & & 1.0 & $-.17^{*}$ & $41^{* *}$ & المقبولية(3) \\
\hline & & & & & & 1.0 & $.43^{* *}$ & $-.17^{*}$ & $.49^{* *}$ & الضمير (4) \\
\hline & & & & & 1.0 & $.11^{*}$ & .03 & $08^{* *}$ & $18^{* *}$ & الانفتاحية(5) \\
\hline & & & & 1.0 & $.14^{* *}$ & $.26^{* *}$ & $.31^{* *}$ & -.03 & $.26^{* *}$ & التدين(6) \\
\hline & & & 1.00 & $-.10^{*}$ & .07 & $-.37^{* *}$ & $-.34^{*}$ & $32^{* *}$ & $-.41^{* *}$ & القلق(7) \\
\hline & & $\begin{array}{c}1.0 \\
0\end{array}$ & $-.24^{*}$ & $.28^{* *}$ & $.15^{* *}$ & $.52^{* *}$ & $.41^{* *}$ & $-.10^{*}$ & $.52^{* *}$ & الصمود (8) \\
\hline & 1.0 & -.09 & $.34^{* *}$ & $.10^{*}$ & $.09^{*}$ & $-.12^{* *}$ & .040 & $.35^{* *}$ & -.08 & الخوف(9) \\
\hline 1.0 & -.09 & $.54^{*}$ & $-.36^{*}$ & $.29^{* *}$ & $.09^{*}$ & $.50^{* *}$ & $.45^{* *}$ & $-.17^{*}$ & $.55^{* *}$ & جودة الحياة \\
\hline
\end{tabular}

0.05 مال عند 0.01 ، 0.0

استقر اءاً لمصفوفة الارتباط يتضح ان جودة الحياة في ظل جائحة كورونا ارتبطت ارتباطاً موجباً

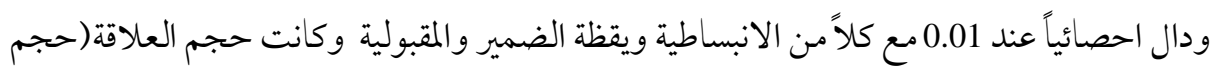
التأثير) كبير مع الانبساطية ويقظة الضمير بينما متوسط مع المقبولية، وارتبطت جودة الحياة ارتباطاً موجباً ودال احصائياً عند 0.05 مع الانفتاحية بحجم علاقة ضعيفة، وارتبطت مع عامل العصابية ارتباطاً سالباً ودال احصائياً عند 0.01 بحجم تأثير ضعيف وهذا يتفق مع التحليل النظري وهو الانسان الانبساطي وذو الضمير والمشارك الاخرين والمتعاطف اكثر جودة للحياة من الانسان الذي يتميز بالعصابية وهذا يتفق مع التراث البحثي (ابو هاشم، 2010; القحطاني، 2017; Remero et al )، 2009. وارتبطت جودة الحياة مع التدين ارتباطاً مو جباً دال عند 0.01 بحجم ارتباط ضعيف وهذا يتفق 
1985)، 2007 Witter et al.، 2015; Rule،Abdalla et al. ،; مع (ابو عمرة، 2014; جان، 2008 ؛ في حين ارتبطت جودة الحياة ارتباطاً موجباً ودال عند 0.01 وبحجم كبير مع الصمود النفيي وهذا يتفق مع (الخشن، 2018، عبد الله، .Zhang et al)، 2020; 2017 ـ ـوارتبطت جودة الحياة ارتباطاً سالباً

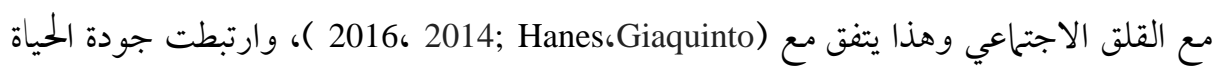
بالخوف من كورونا ارتباطاً سالباً بدرجة ضعيفة جداً ودالة عند 0.05 والدلالة نتيجة كبر حجم العينة وهذ يتفق مع التحليل المنطقي حيث زيادة الخوف يؤدي إلى عدم الصحة النفسية وبدوره جودة حياة منخفضة ولكن صغر حجم الارتباط مفاده لا شيء مشترك بين جودة الحياة والخوف من كورونا ويبدو ان هذا هو الحال في البيئة المصرية على الاخص و العربية عموماً.

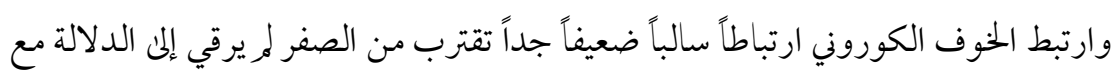

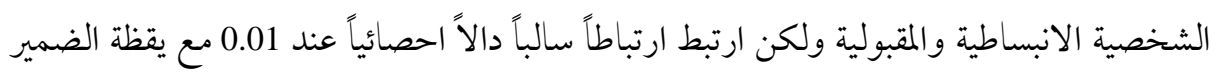
و هذا مفاده ان الشخصية علن القادرة على تحمل المسئولية والاتقان و العمل الجـاد والالتز ام بالقو اعد اقل خوفاً من الاصابة بجائحة كورونا؛ بينما ارتبطت الانفتاحية ارتباطاً موجباً مع الخوف ودال احصائياً

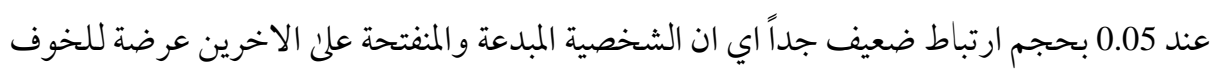
من كورونا بدرجة ضعيفة؛ بينها ارتبطت العصابية ارتباطاً مو جباً ودال عند 0.01 مع الخوف من كورونا وبحجم تأثير متو سط بمعني انه كلما كانت الشخصية عصبية فهي اكثر عرضة للخوف بكورونا وهذه

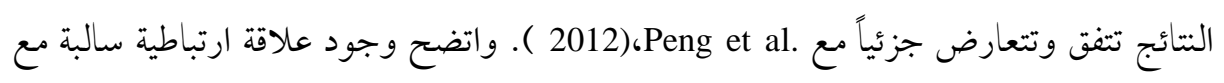
الصمود النفسي بحجم ارتباط ضعيف وهذا مفاده كلما ارتفعت درجة الصمود النفسي كان الفرد اقل

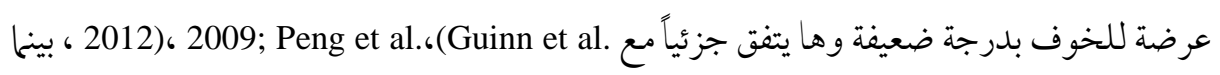

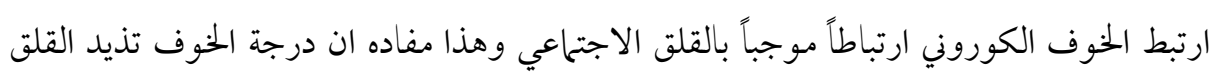
الاجتماعي عند الأفراد. ولكن النتيجة التي تحتاج إلى ان نقف عندها هو وجود ارتباط موجب ودال احصائياً عند 0.05 بين التدين والخوف من كورونا بحجم ارتباط ضعيف جداً ويمكن القول ان الدلالة 
نشأت نتيجة كبر حجم العينة وليس نتيجة لواقعيتها ويمكن القول لا علاقة فعلية بينها وهذا يتناقض مع المبادئ والقو اعد الاسلامية. بينما ارتبط القلق الاجتماعي ارتباطاً سالباً مع مكونات الشخصية الانبساطية والمقبولية ويقظة الضمير وارتباطاً موجباً مع العصابية وهذا يتفق مع (2015)، 2008; Shi et al.،(Morris \& Gilliland

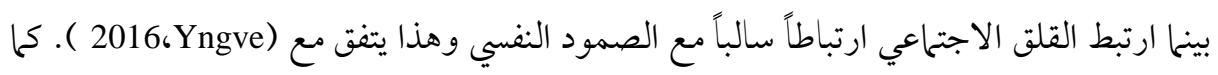
يوجد ارتباط سالب بين القلق الاجتحاعي والتدين لكنه من النوع الضعيف. الاجابة على السؤال الخامس: تم اجر اء تحليل المسار في إطار نمذجة المعادلة البنائية للتحقق من النموذج المفترض باستخدام طريقة الاحتمال الأقصن واعطي مؤشرات المطابقة كالتالي:

Goodness of Fit Statistics

Degrees of Freedom $=0$

Minimum Fit Function Chi-Square $=0.00(\mathrm{P}=1.00)$

Normal Theory Weighted Least Squares Chi-Square $=0.00(\mathrm{P}=1.00)$

The Model is saturated, the Fit is Perfect!

وهذا يعني ان النموذج في بجمله استهلك كل تباينات الارتباطات بين المتغيرات وهو مطابقة بدرجة تامة للبيانات وهذا يرجع إلى الخلفية النظرية الجيدة التي ساعدت علن بناء المسارات بين المتغيرات. وفيما يلي قيم التأثيرات السبية بين المتغيرات:

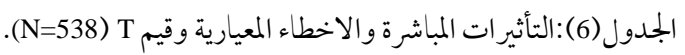

\begin{tabular}{|c|c|c|c|c|}
\hline الصمود النفسي & القلق الاجتاعي & الخوف الكوروني & جودة الحياة & \\
\hline $\begin{array}{c}0.29 \\
0.04 \\
(\mathrm{~T}=7.14)\end{array}$ & $\begin{array}{c}-0.26 \\
0.04 \\
(\mathrm{~T}=-5.97)\end{array}$ & $\begin{array}{c}-0.03 \\
0.05 \\
(-0.53)\end{array}$ & $\begin{array}{c}340 . \\
\mathrm{SE}=0.04 \\
(\mathrm{~T}=8.32)\end{array}$ & الانبساطية \\
\hline $\begin{array}{c}0.03 \\
0.03 \\
(0.73)\end{array}$ & $\begin{array}{c}0.21 \\
0.04 \\
(5.61)\end{array}$ & $\begin{array}{c}0.33 \\
0.04 \\
(8.02)\end{array}$ & $\begin{array}{c}-0.04 \\
0.03 \\
(-1.06)\end{array}$ & العصابية \\
\hline $\begin{array}{c}0.14 \\
0.04 \\
(3.57)\end{array}$ & $\begin{array}{c}-0.14 \\
0.04 \\
(-3.28)\end{array}$ & $\begin{array}{c}0.03 \\
0.05 \\
(0.65)\end{array}$ & $\begin{array}{c}0.18 \\
0.04 \\
(4.61)\end{array}$ & المقبولية \\
\hline
\end{tabular}




\begin{tabular}{|c|c|c|c|c|}
\hline الصمود النفسي & القلق الاجتاعي & الخخوف الكوروني & جودة الحياة & \\
\hline $\begin{array}{c}0.29 \\
0.04 \\
(7.18)\end{array}$ & $\begin{array}{c}-0.17 \\
0.04 \\
(-3.82)\end{array}$ & $\begin{array}{c}-0.10 \\
0.05 \\
(-2.14)\end{array}$ & $\begin{array}{c}0.23 \\
0.04 \\
(5.72)\end{array}$ & يقظة الضمير \\
\hline $\begin{array}{c}0.05 \\
0.03 \\
(1.36)\end{array}$ & $\begin{array}{c}0.12 \\
0.04 \\
(3.10)\end{array}$ & $\begin{array}{c}0.06 \\
0.04 \\
(1.48)\end{array}$ & $\begin{array}{c}-0.01 \\
0.03 \\
(-0.31)\end{array}$ & الانفتاحية \\
\hline $\begin{array}{c}0.08 \\
0.04 \\
(2.12)\end{array}$ & $\begin{array}{c}0.05 \\
0.04 \\
(1.18)\end{array}$ & $\begin{array}{c}0.13 \\
0.04 \\
(2.91)\end{array}$ & $\begin{array}{c}0.09 \\
0.04 \\
(2.44)\end{array}$ & التدين \\
\hline- & $\begin{array}{c}0.06 \\
0.05 \\
(1.18)\end{array}$ & $\begin{array}{c}-0.09 \\
0.05 \\
(-1.87)\end{array}$ & $\begin{array}{c}0.24 \\
0.040 \\
(5.89)\end{array}$ & الصمود النفسي \\
\hline- & & $\begin{array}{c}0.29 \\
0.050 \\
(6.36)\end{array}$ & $\begin{array}{c}-0.09 \\
(0.04) \\
(-2.29)\end{array}$ & القلق الاجتماعي \\
\hline & & & $\begin{array}{c}0.01 \\
0.04 \\
(0.21)\end{array}$ & الخوف الكوروني \\
\hline
\end{tabular}

القيمة الأولي: قيمة التأثير (معامل الانحدار)، الثانية: الخطأ المعياري، الثالثة: قيمة Tل يتضح من الجدول(6) وجود تأثير موجب ودال احصائياً من عوامل الشخصية الانبساطية ويقظة الضمير والمقبولية إلى جودة الحياة بمعني كلما كان الفرد متفائل ولديه مشاركة اجتماعية وثقة

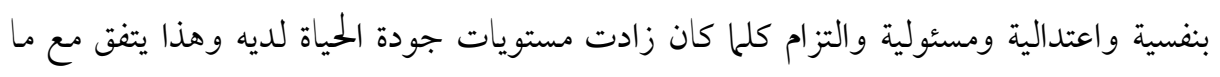
، 2017)، 2018; Ponet et al.،Lachman et al. توصلت اليه(ابو هاشم، 2010; القحطاني، 2017 ولكن العصابية ليس ها تأثير دالة علن جودة الحياة وهذا يتناقض مع (ابو هاشم، 2010; القحطاني، 2017; السيكولوجي بان الشخص العصبي متوتر وسريع الغضب وحزين ومتشائم وهذا بدوره يؤدي إلى مستويات منخفضة من جودة الحياة وكذلك يتناقض مع نتائج الدراسة الارتباطية حيث توصلت إلى علاقة ارتباطية سالبة 0.18- من النوع الضعيف لكن هذا الارتباط تلاشي في نتائج تحليل المسار. كما 
اتضح ان للتدين والصمود النفسي تأثير موجب على جودة الحياة وهذا يتفق مع التحليلات النظرية من واقع القران والسنة حيث ان التدين يزيد من مستويات الطمأنينة والسكينة والرضا لدي الفرد والمستويات العالية من المثابرة والتفاؤل والشجاعة علن مو اجهة الشدائد تنعكس بالايجاب على حياة

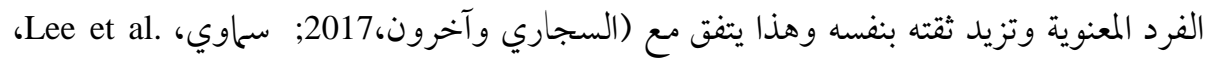
2013،2008;Rule جودة الحياة لدي المرضي وهذا يتفق مع 2014)، 2016; Sarma \& Byrne،(Hanes بالنسبة للخوف الكوروني، يتضحمن الجدول(6) ان زيادة القلق الاجتماعي والعصابية يُسببوا زيادة مستويات الخوف الكوروني وهذا يتضح من خلال التأثيرات الموجبة ويبدو هذا منطقي حيث الانسان العصابي اقل قدرة في التحكم في انفعالاته واكثر عرضة للتوتر والخوف والانهيار النفسي (Roselline \& Brown الكوروني وهذا يتعارض مع . 2015) ، 2012; Shi et al.، (Min et al. و كذلك يتعارض مع نتائج التحليلات الارتباطية في الدراسة؛ كما يوجد تأثير سالب من يقظة الضمير إلى الخوف الكوروني بمعني

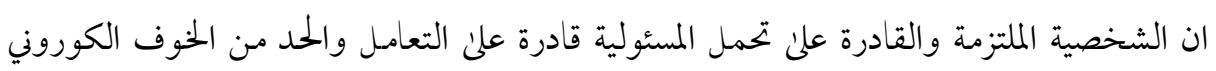
والاضطر ابات النفسية المتعلقة به بدرجة ضعيفة. واتضح ان الصمود النفسي ليس له دور في تخفيف او

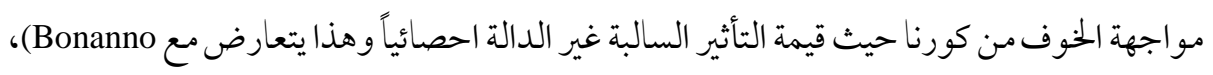
. 2012)، 2019; Peng et al.،2008; Ovaska-Stafford et al. الكوروني حيث علن الرغم ان قيمة التأثير موجبة وضعيفة ولكنها دالة احصائياً عند 0.01 وهذا يتعارض مع الحقيقة القائلة كلما زاد مستوي التدين ينخفض مستوي الخوف من المرض حيث ان الفرد الفرد يعتبر ان المرض ابتلاء من الله وعليه الرضا به و كذلك يتناقض جزئياً مع التحليل الكيفي للتراث البحثي لـ ـKoenig et al، (2001) حيث توصل إلى ان 46\% من الدراسات بين المتغيرين توصلت إلى علاقة سالبة بينما 31.6\% توصلت إلى لا علاقة و 13.16\% توصلت إلى علاقة موجبة. 
وبالنسبة للخوف الاجتاعي يتضح أن المستويات العالية من الانبساطية والمتبولية ويقظة

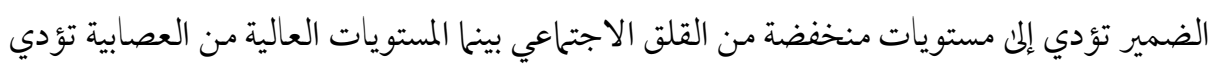

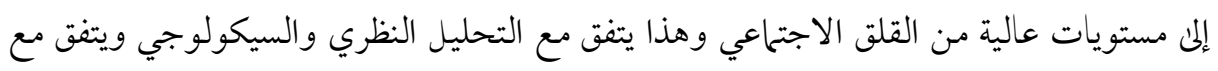
أم الملفت للانتباه أن 2015)، 2011; Shi et al.، 2016; Roselline \& Brown،(Abbasi-Asi et al. المستويات العالية من الانفتاحية تؤدي إلى مستويات عالية من الخوف الاجتاعي وهذا مفاده ان الأفراد الذين لديهم حب الاستطلاع وتحر من القيو دلديهم مستويات عالية من القلق الاجتماعي وأكثر ارتباكاً

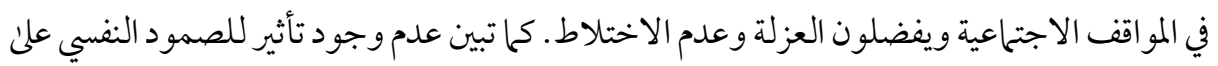

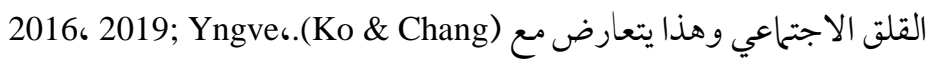

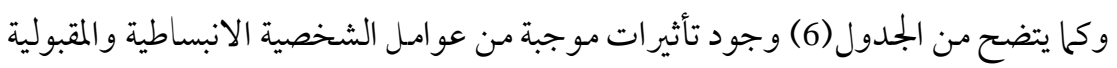

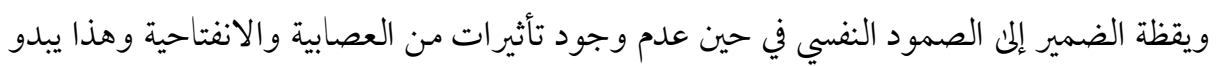

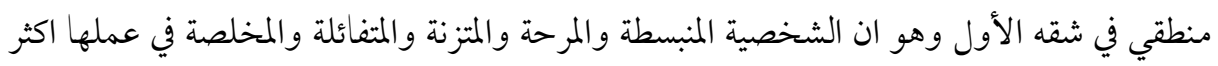

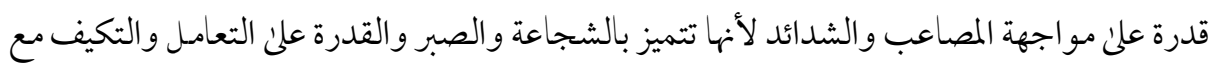

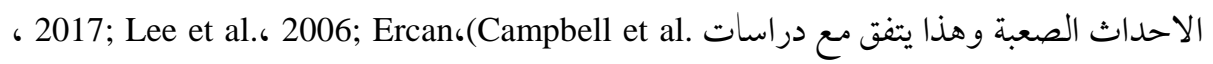
.2018;)،2008; Oshio et al. (2010)،Fayombo

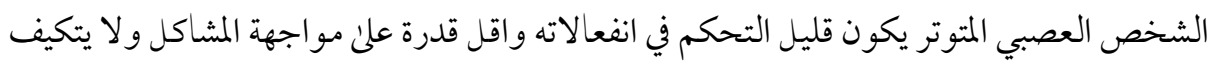

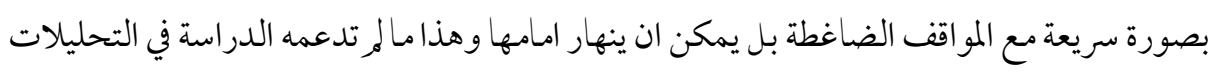

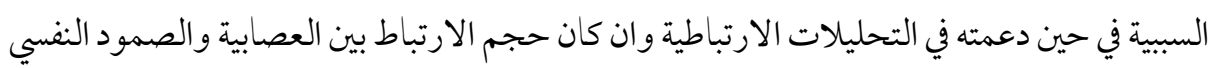

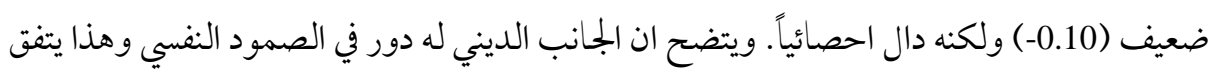

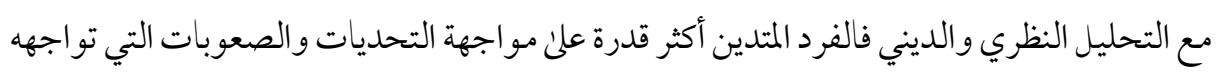
في حياته. 
Prof. Dr. abdenasser Alsayed Amer

Volume (3) No. (4) 2020

التأثيرات غير المباشرة من المتغيرات الخارجية المستقلة مكونات الشخصية والتدين إلنا جودة

$$
\text { الحياة والخوف الكوروني والخوف الاجتماعي: }
$$

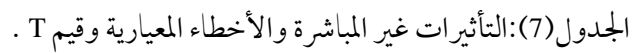

\begin{tabular}{|c|c|c|c|}
\hline الخوف الاجتيا= & الخوف الكوروني & جودة الحياة & المثغيرات \\
\hline $\begin{array}{c}-0.02 \\
0.01 \\
(\mathrm{~T}=-1.17)\end{array}$ & $\begin{array}{c}-0.10 \\
0.03 \\
(\mathrm{~T}=-4.44)\end{array}$ & $\begin{array}{c}0.10 \\
\mathrm{SE}=0.02 \\
(\mathrm{~T}=4.89)\end{array}$ & الانبساطية \\
\hline $\begin{array}{c}0.01 \\
0.01 \\
(1.17)\end{array}$ & $\begin{array}{c}0.06 \\
0.01 \\
(3.98)\end{array}$ & $\begin{array}{c}-0.01 \\
0.02 \\
(-0.67)\end{array}$ & العصابية \\
\hline $\begin{array}{c}0.01 \\
0.01 \\
(1.12)\end{array}$ & $\begin{array}{c}-0.06 \\
0.02 \\
(-3.35)\end{array}$ & $\begin{array}{l}0.05 \\
0.01 \\
3.55\end{array}$ & المقبولية \\
\hline $\begin{array}{c}0.02 \\
0.01 \\
(1.17)\end{array}$ & $\begin{array}{c}-0.08 \\
0.02 \\
(-3.57)\end{array}$ & $\begin{array}{c}0.09 \\
0.02 \\
(4.91)\end{array}$ & يقظة الضمير \\
\hline $\begin{array}{c}0.00 \\
0.00 \\
(0.00)\end{array}$ & $\begin{array}{c}0.03 \\
0.01 \\
(2.34)\end{array}$ & $\begin{array}{l}0.01 \\
0.01 \\
0.14\end{array}$ & الانفتاحية \\
\hline $\begin{array}{c}0.00 \\
0.00 \\
(0.00)\end{array}$ & $\begin{array}{c}0.01 \\
0.01 \\
(0.51)\end{array}$ & $\begin{array}{c}0.02 \\
0.01 \\
(1.43)\end{array}$ & التدين \\
\hline
\end{tabular}

يتضح وجود تأثير غير مباشر موجب من الانبساطية والمقبولية ويقظة الضمير إلى جودة الحياة من خلال القلق الاجتاعي والصمود النفيي والخوف، وتأثير غير مباشر سالب من الانبساطية و المقبولية ويقظة الضمير إلى الخوف وهذا لم يتحقق من خلال التأثير المباشر للانبساطية والمقبولية لأنه يمكن للانبساطية والمقبولية ان تذيد الصمود النفيي وتحفض القلق الاجتماعي وبدورهما يخفضوا الخوف من الاوبئة، وتأثير غير مباشر موجب من العصابية إلمى الخوف من خلال الصمود النفسي والقلق الاجتماعي. 
وفيما يلي النموذج السبي بمسار اته الدالة احصائياً:

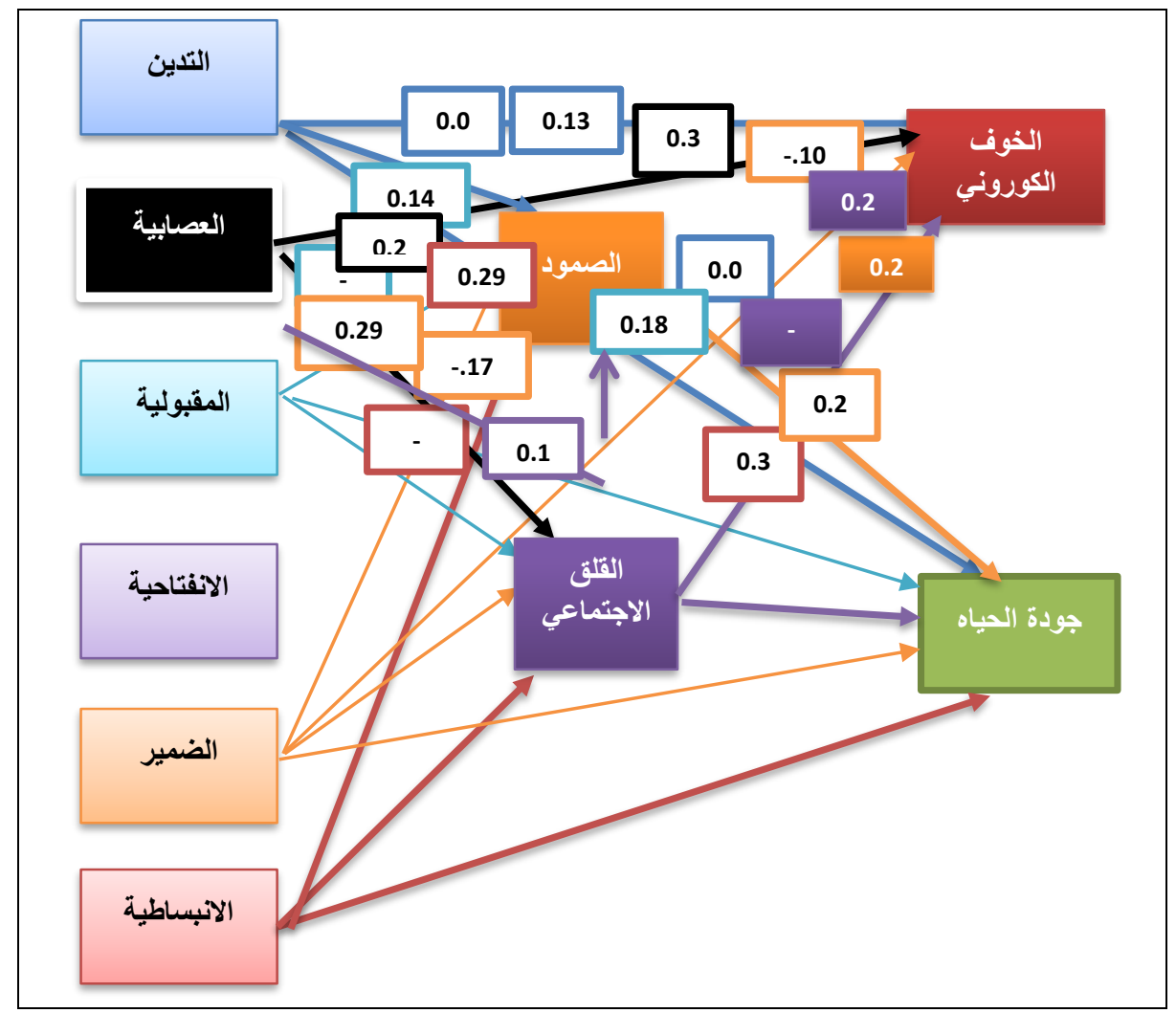

الشكل(2): النموذج السبي بمسار اته الدالة احصائياً

المناقشة والتعليق

هدفت الدراسة إلى تحديد مستوي جودة الحياة والخوف الكوروني والصمود النفسي في ظل جائحة كورونا لدي عينة من المجتمع العربي، وتوصلت إلى أن أفر اد العينة يعانوا من الحوف الكوروني بدرجة متوسطة وكانت أقل مظاهر الخوف هو حدوث أحلام يقظة وكو ابيس مرعبة خوفاًمن الاصابة من كورونا وهذا يدل علن ان موضوع كورونا لا يشغل حيز التفكير العميق في حياة الأفراد. كما توصلت الدراسة إلى توفر مستوي جودة الحياة بدرجة كبيرة في ظل هذه الأزمة حيث لم تؤثر هذه الأزمة في معظم مظاهر جودة الحياة الاجتماعية والنفسية لدي افراد العينة وكانت أكثر مظاهر جودة الحياة تو افراً هي أن 
العلاقات مع الو الدين والاصدقاء والعلاقات العائلية متوفرة بدرجة كبيرة بالتالي له تتغير هذه العلاقات كثيراً في ظل هذه الأزمة بينا كانت أقل مظاهر الجودة هي المشاعر السلبية لدي الأفراد من احباط واكتئاب وقلق. ويتضح أن الصمود النفسي متوفر بدرجة كبيرة وهذا يزيد من قدرة الأفراد علن علي مواجهة الصعاب والاثار السلبية المرتبطة بجائحة كورونا وكانت أكثر مظاهر الصمود توافراً هي الاصرار والعزيمة علن تحقيق الاهداف. وبالنسبة للتحليلات الوصفية لمتغيرات الدراسة أظهرت افراد

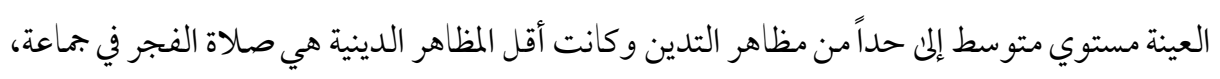
والحرص علن أداء الاذكار، وقر اءة وسماع الاحاديث بينما كانت أكثر المظاهر الدينية هي الدعاء إلى الله، و التو كل عليه، والخشوع و الطمأنينة عند سماع القران من التدين (M=13.052 ) و أظهرت التحليلات أن أفراد العينة يعانون من مستويات متوسطة من القلق الاجتماعي.

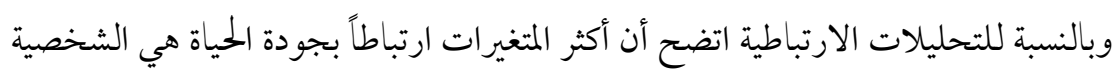

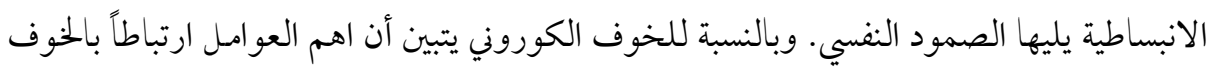
هي الشخصية العصابية والقلق الاجتماعي وهذا يبدو متناسق مع النظرية والتحليل المنطقي. ولكن

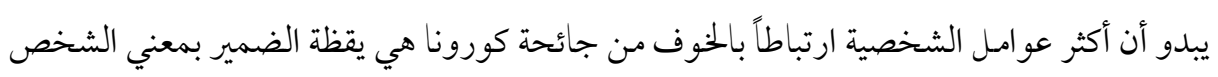
المعتدل المثابر ذو مسئولية أكثر قدرة علن التغلب علن الخوف الكوروني. بالنسبة للتأثيرات السبية بين متغيرات الدراسة يتضح أن من أكثر المتغيرات التي اسهامًاً في جودة الحياة عند الفرد هي الصمود النفسي وهذا تؤيده معظم الدراسات في مجال علم النفس الايجابي

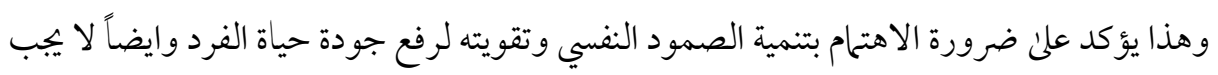
إغفال مكونات الشخصية وهي علئ الترتيب الانبساطية ويقظة الضمير والمقبولية في تنمية وزيادة جودة الحياة ولكن إذا دققنا في قيمة حجم التأثيرات على جودة الحياة نلاحظ أن معاملات الانحدار كلهامن النوع الضعيف ماعدا الصمود الاكاديمي كان من النوع المتوسط والدلالة الاحصائية كانت نتيجة

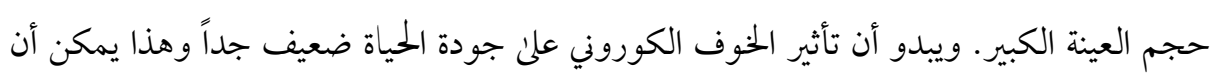


يعطي انطباع بان الفرد في البيئة العربية يتعايش مع هذا الوضع بدون أحداث تأثير سلبي علن جودة حياته.

بالنسبة للخوف الكوروني يتبين أن من أهم العوامل التي تسهم بزيادة الخوف هي الشخصية العصابية والقلق الاجتماعي وهذا يبدو متناسق مع النظرية والتحليل المنطقي بمعني الشخص المنطوي المتوتر والعصبي الانعز الي الذي يخشئ من العلاقات الاجتماعية أكثر عرضة للخوف الكوروني، بينما التدين والصمود النفسي من المتغيرات التي تمثل حائط صد ضد الخوف من جائحة كورونا علن الرغم من القيمة الضعيفة لقيمة التأثيرات لهم). ولكن النتيجة التي تستحق ان نقف عندها بالتأمل والتفسير هي انه كلما زادت درجة التدين وتأدية الفروض والنوافل كلما زادت درجة الخوف من جائحة كورونا لكن لماذا هذه التيجة؟؟، بكل تأكيد توجد تفسيرات لها ومن اهم هذه التفسيرات هي

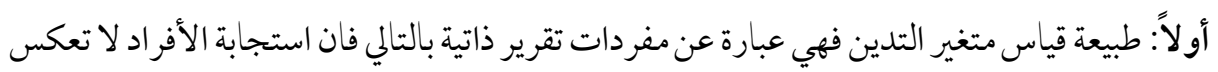

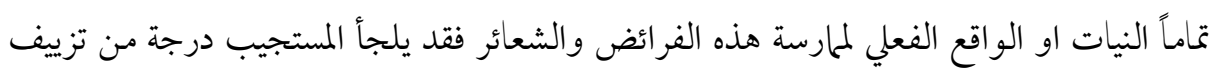
استجابته حتى لا يظهر بصورة انه يخالف التعاليم والفرائض الاسلامية او لا يقال عنه انه غير مؤمن. ثانياً: طبيعة عينة الدراسة حيث انها من مستخدمي وسائل التو اصل الاجتماعي وقيامها بممارسات عديدة والتجوال عبر الانترنت قد يشغلها علن تعميق او تأدية النواحي الدينية مقارنة بالأشخاص العاديين البسطاء من الطبقات الاجتماعية. ثالثاً: الكتاب والسنة يعترفان بالخوف الفطري الغريزي ومنه الخوف من جائحة كورونا باعتبارها هلاكاً للنفس بدرجات مختلفة والخوف كل ما يوقع الضرر بالشخصية وتوجد في التراث الاسلامي مو اقف في الغزوات تصور تأثير الخوف علئ المسلمين وهذا لا يتنافن مع شدة الايهان في حياة الرسول صلي الله عليه وسلم. رابعاً: قد يقيس مقياس الخوف من كورونا الذعر والرهبة والتخويف الشديد وهذا يمثل اتجاه متطرف

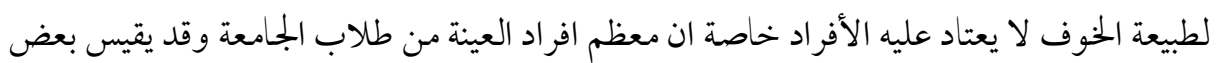


السلو كيات التي تدعو للحرص والحذر وتجنب اموراً معينة خوفاً علن حياتهم. خامساً: درجة الايحان له تصل إلى الدرجة الكافية من العمق و اليقينية لأفراد العينة بدليل ان درجة التدين لمتكون قوية بل درجة متوسطة. بصفة عامة هذه النتيجة تحتاج إلى تأكيد من دراسات علن عينات وثقافات وازمنة مختلفة. ودعمت الدراسة الفرضية أن الجانب الديني يذيد من قدرة الفرد علن مواجهة الصعاب ويذيد من درجة صموده النفسي حيث قيمة التأثير ضعيفة جداً ولكنها دالة وتم تدعيمه في الدراسة الارتباطية حيث كانت قيمة معامـل الارتباط من النوع تقترب من المتوسط 0.28 ولكن لماذا تلاشي هذا في الدراسة السبية يبدو أن تأثير متغير مع آخر غير تأثيره في شبكة مجمعة من المتغيرات فان تأثيره في شبكة العلاقات يكون أكثر توزيعاً لقوته الارتباطية علن بقية المتغيرات. و الشيء الذي تؤكد الدر اسة عليه هو الدور الذي لئي يلعبه مكون يقظة الضمير في تقليل الخوف من كورونا بالإضافة إلى تأثير الانبساطية والمقبولية من خلال متغيرات الصمود والقلق الاجتماعي في تخفيف الخوف الكوروني. والملفت للنظر وجود فروق بين العينة المصرية والعينة العربية غير المصرية في جودة الحياة

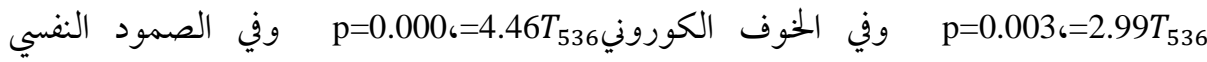
p=0.00،5.60T 5336 (لصالح غير المصرية). ولذلك تم اجرا تحليل للنموذج السببي للعينة المصرية فقط وكانت النتائج تتقارب مع نتائج العينة الاجمالية فيا عدا أن التدين لميكن له تأثير علن جودة الحياة و اتضح ان التدين والمقبولية ها تأثير سابي علن الخوف الكوروني. وتم اجراء تحليل النموذج السببي للعينة غير المصرية حيث كانت الاخطاء المعيارية كبيرة تقترب 0.11 حيث فمثلاً قيمة التأثير 0.21 تعطي قيمة T غير دالة احصائية في حين كانت نفس القيمة في البيئة المصرية تعطي دلالة (T=5.05)، بالتالي الاعتماد علن نتائج نموذج العينة غير المصرية غير موثوق به علن الاطلاق نتيجة صغر حجم العينة.

من نقاط القوة للدراسة اعتمادها على الصيغ المختصرة للمقاييس وانعكس هذا على اتساقها الداخلي حيث تمتعت بدرجة جيدة من الثبات تقترب من 0.90 ودرجة عالية من الصدق البنائي حيث اعطي التحليل العامل الاستكشافي أبعاد للمقاييس ذات قيمة تفسيرية ومنطقية عالية وايضاً من خلال 
بيانات هذه المقايس التي امدتنا بنتائج تتفق مع التراث البحثي في مجال جودة الحياة والخوف والصمود النفسي ومن هنا يجب ألا يبني الباحث مقاييسه طويلة تبعث علني الملل.

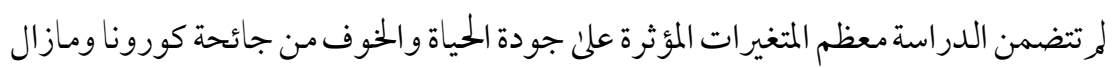
هناك العديد من التساؤلات حول دور العديدمن المفاهيم النفسية لان ما تضمنته الدراسة من متغيرات

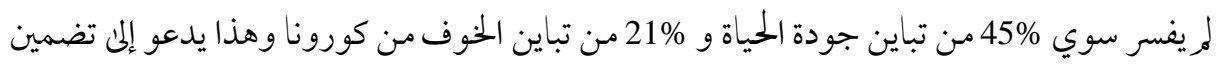

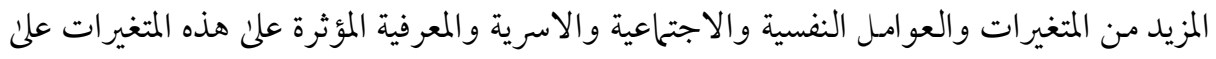

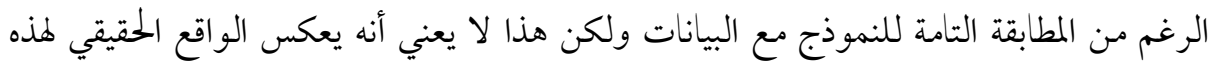

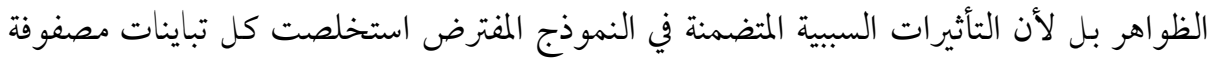

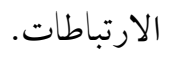

للدراسة بعض محددات وهو أن الوصول لاستدلالات سبية من الارتباطات بين المتغيرات

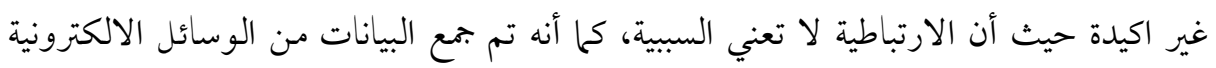

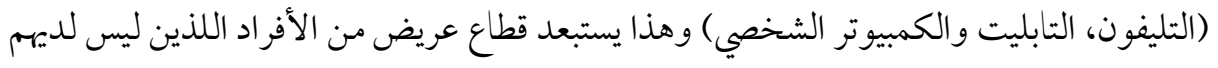

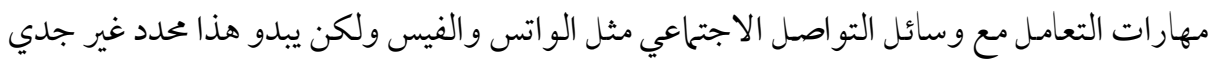

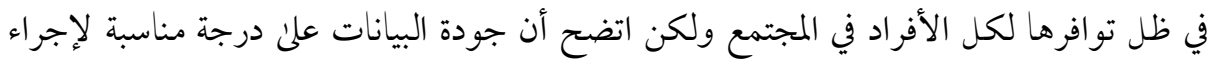

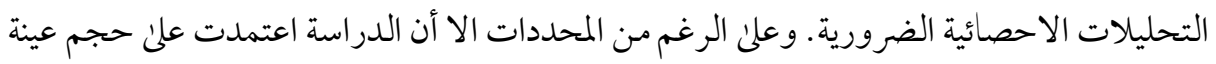

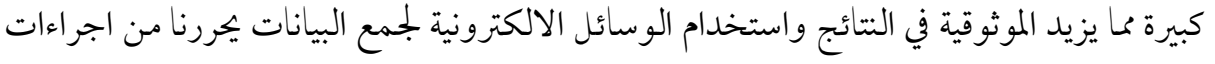

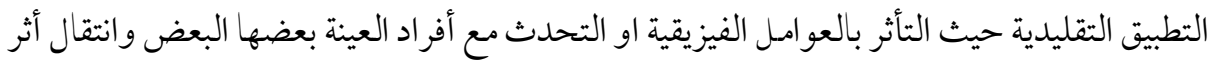

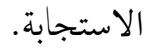

وتنبع اهمية الدراسة في تناول ظاهرة الحوف من جائحة كورونا باعتبارها من الظو اهر الطارئة

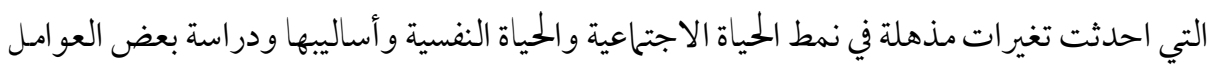
المسببة لجودة الحياة ولحوف من كورونا والكشف عن دينامية العلاقات بين هذه العوامل للمساعدة 
للوصول إلن فهم أفضل لهذه الظاهرة مما يساعد علن بناء برامج ارشادية وعلاجية تركز علن اهم

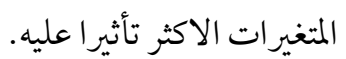
ولابد من التأكيد علنا أهمية عامل يقظة الضمير لما يتضمنه من مثابرة وتحمل مسئولية تساعد الفرد علن استعادة توازنه النفسي في مواجهة المحن مثل الذي نعيشه هذه الايام من جائحة كورونا،

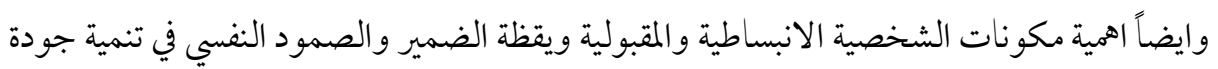
الحياة نتائج الدراسة غير قابلة علن التعميم الا إذا الجريت دراسات اخري تأكيدية علني عينات اخري في البيئة العربية حيث كانت عينة الدراسة في غالبيتها من البيئة المصرية 82.2\% وهذا يعطي شكوك حول تعميم نتائج الدراسة علن المجتمع العربي بصفة عامة.

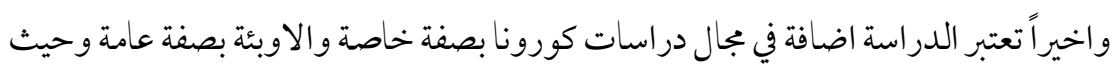

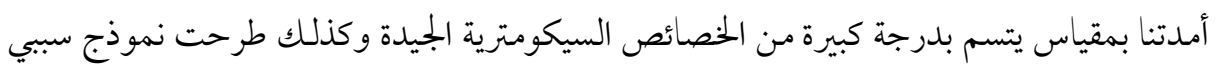
فسر شبكة العلاقات السبية بين العديد من الجوانب النفسية والشخصية والدينية في ظلل جائحة

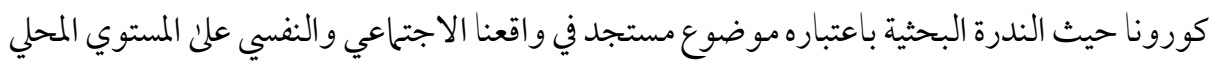
والعربي والعالمي. 
ابليش، حواء أبراهيم. (2016). الاسهام النسبي للصمود النفسي والامتنان في التنبؤ بالرضا عن الحياة

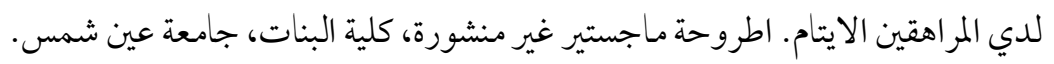

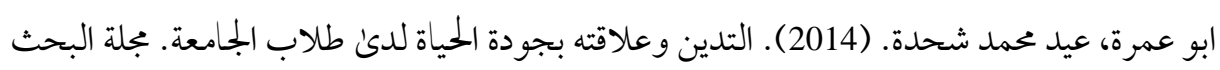

$$
\text { العلمي في التربية، 3، 189-210. }
$$

ابو هاشم، السيد محمد. (2010). النموذج البنائي للعلاقات بين السعادة النفسية والعوامل الخمسة النسة

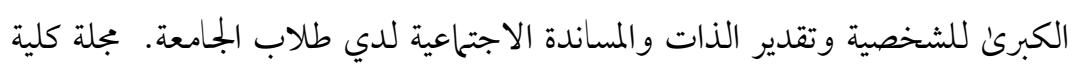

$$
\text { التربية، جامعة بنها،20 350-368. }
$$

الأمد، أمد عبدالله، عمر، ماجدة أحمد، هديب، أبجد أممد ـ (2017). الأخلاقيات الرقمية والحداثة

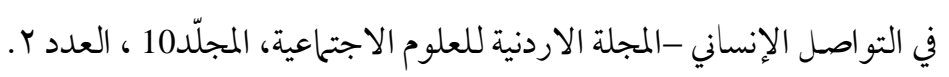

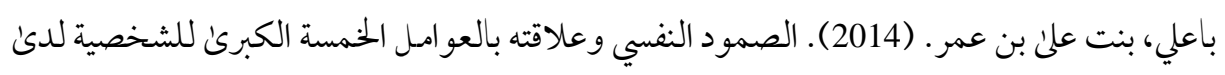

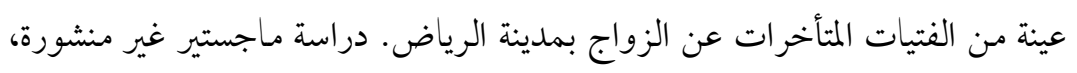

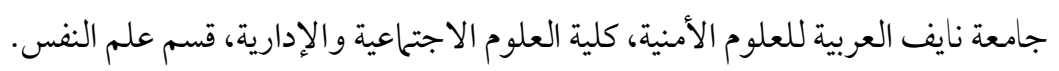

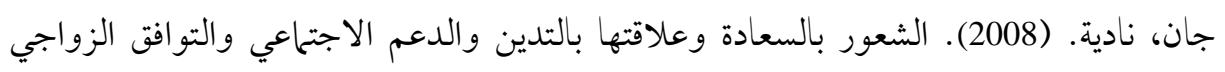

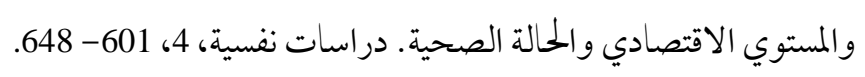

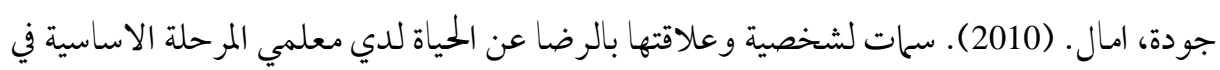

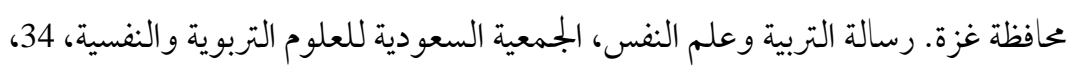
$.43-11$

الخشن، منخ نبيل عبدالمعبود. (2018). نمذجة العلاقات السبية بين الصمود النفسي والرضا المهني

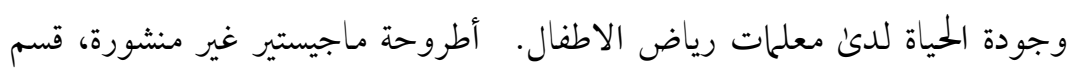
دراسات الطفولة، كلية الدراسات العليا للتربية، جامعة القاهرة. 
درويش، زينب عبد المحسن. (2016). الانبساطية والمساندة الاجتماعية كمنبئات بالصمود النفسي لدى النساء الارامل في ضوء بعض المتغيرات الديمواجرافية. مجلة كلية الآداب، جامعة طنطا،

$$
\text { .1444-1389، }
$$

السجاري، مها مشاري، والقعود، ابتسام راشد والخرينج، انوار فارس (2017). التدين والدعم الاجتماعي وعلاقته بجودة الحياة لدي المصابين بالسرطان من الرجال في الكويت. مجلة

$$
\text { دراسات الخليج والجزيرة العربية، 43، } 91 \text { - } 126 .
$$

سماوي، فادي سعود. (2013). السعادة وعلاقتها بالذكاء الانفعالي والتدين لدي طلبة الجامعة

$$
\text { الاسلامية العالمية. مجلة العلوم التربوية، 40، 729- } 747 .
$$

شاهين، هيام صابر صادق. (2017). اليقظة العقلية كمتغير معدل للعلاقة بين القلق الاجتماعي وجودة الحياة المدركة لدي المر اهقين المكفوفين. دراسات نفسية(رانم)، 27، 507-526.

صباح، عايش صباح والشجسري، عمر خلف. (2017). جودة الحياة الروحية وعلاقتها بالحصانة النفسية لدئ طلبة الجزائر والعراق دراسة ميدانية علن طلبة جامعتي الانبار وسعيدة. مجلة

$$
\text { جامعة الانبار للعلوم الانسانية، 3، 422-450. }
$$

عامر، عبد الناصر السيد. (2018). نمذجة المعادلة البنائية للعلوم النفسية والاجتماعية: الاسس

$$
\text { و التطبيقات (الجزء الأول). الرياض: دار جامعة نايف للنشر. }
$$

عامر، عبد الناصر السيد. (2019). بناء الاختبارات والمقاييس النفسية: الاسس والتطبيقات. الرياض:

$$
\text { مكتبة العبيكان الرقمية. }
$$

عبدالله، نسمة محمد بكر. (2020). الصمود النفسي ونوعية الحياة كمنبئات بالدافعية المهنية لدى معلمات رياض الاطفال. أطروحة ماجيستير غير منشورة، قسم علوم نفسية، كلية التربية للطفولة

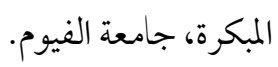


عرفشة، نوف غازي (2018). التوجه الديني وعلاقته بمعنى الحياة والتفكير العقلاني لدئ طلاب

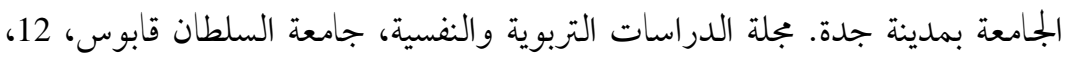

$$
.624-605
$$

القحطاني، ظافر بن محمد. (2017) . جودة الحياة وعلاقتها بالسمات الشخصية لدي الطلاب الجامعيين. جلة العلوم الانسانية والاجتماعية، جامعة الملك محمد بن سعود الاسلامية، 45، 346-289. 


\section{References:}

Abbasi-Asi، R، Naderi، H.، \& Akbari، A. (2016). Predicting female students social anxiety based on their personality traits. Journal of Fundamentals of Mental Health، 18، 433-349.

Abdala، G. A.، Kimura، M. Koenig، H. G.، Reinert، K. G.، Horton، K. (2015). Religiosity and quality of life in older adults: Literature review. Life Style Journal، 2، 25-51.

Ahorsu‘ D. K.، Lin` C. Y.، Imani، V.، Saffari، M. (2020). The fear of covid-19 scale: Development and intial validation. International Journal of Mental Health and Addiction، 27، 1-9. https//doi.org/10.1007/s11469-020-00270-8

Caballo، V. E.، Salazar، I. C.، Irurtia، M. J.، Arias، B.، \& Nobre، L. (2013). The assement of social anxiety through five self report measures، LSAS-SR، SPAI SPIN، andcSIAS: A critical analysis of their factor structure. Behavioral Psychology، 21، 423-448.

Campbell-Sills، 1..، Cohan، S. L. \& Stein، M. (2006). Relationship of resilience to personality، Coping، and psychiatric symptoms in young adults. Behavior Research and Therapy، 44، 585-599.

Conner، K. M.، \& Davidson، J. R. (2003). Development of a new resilience: The conner-dividson scale (CD-RISC). Depress Anxiety، 18، 76-82.

Fayombo، G. (2010). The Relationship Between Personality Traits and Psychological Resilience among the Caribbean Adolescents. International Journal of Psychological Studies، 2، 105- 116.

Giaquinto، M. B. (2014).Mindfulness، social problem solving، social anxiety and quality of life in college students with Autism Spectrum Disorders. Teachers College، Columbia University، Unpublished ED. Dissertation.

Goldberg، L. R. (1993). The structure of phenotypic personality traits. American Psychologist، 48، 26-34.

Hanes، A. (2016). The impact of social anxiety and sensory processing sensitivity on quality of life. Unpublished doctoral dissertation، Michigan school of Professional Psychology. 
Kennedy، J. E. (1999). Religious guilt and fear w well-being، and fundamentalism. Retrieved: http/jeksite.org/research/bv.pdf/.

Koenig، H. G.، McCullough، M. E. Larson‘ D. B. (2001). Handbook of religious and health. New York: Oxford University Press.

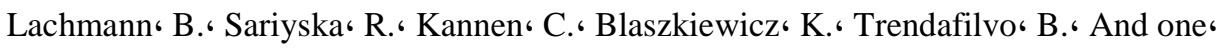
L.، Eibes، M. Markowetz‘ A.، Li، M. Kendrick‘ K. M. \& \& Montag، C. (2018). Contributing to overall life satisfaction: Personality traits versus life satisfaction Revisited: Is replication impossible. Behavioral Sciences، 8. Doi:10.3390/bs8010001.

McCrae، R. R.، \& Costa، R. T. Jr. (1787). Validation of the five-factor model of personality across instruments and observers. Journal of personal and Social Psychology، 52، 81-90.

Martos، T.، Thege، B.، K.، \& Michael، M. F. (2010). It's not only what you hold، it's how you hold it: Dimensions of religiosity and meaning in Life. Personality and Individual Differences، 49، 863-868.

Morris، L. and Gilliland، J. (2008). Social anxiety factor: Relation in introversion and neuroticism. ERIC، ED، 195872.

Nakaya، M. O Oshio، A.، Kaneko، H. (2006). Correlations for adolescent resilience scale with big five personality traits. Psychological reports، 98، 927-930.

Peng، L، ، Zhang، J، Li، M، Li، P، Zhang، Y، Zuo، X، Miao، Y. \& \& Xu، I. (2012). Negative Life events and mental Health of Chinese medical Students: the effect of resilience، Personality and Social Support. Psychiatry Research. Psychiatry Research، 196، 1، 138- 141.

Pocent، C.، Dupuis، M. Congard، A. Jopp، D. (2017). Personality and its links to quality of life: Mediating effects of emotions and self-efficacy beliefs. Moti. Emot. Do 10.1007/s11031-017-9603-0

Rammstedt، B.، \& John، O. P. (2007). Measuring personality in one minute or less: A 10-ite short version of big five inventory in English and German. Journal of Research in Personality، 41، 203-212. 
Romero، E، Villar، P، Luengo، and Gomez- Fraguela، J. (2009). Traits، Personal Strivings and well-being. Journal of Research in Personality ،43، 535- 546.

Rosellini، A. \& Brown، T. (2011). The Neo Five Factor inventory: Latent structure and relationships with Dimensions of anxiety and Depression Disorders in Large Clinical Sample. Assessment، 18، 27-38.

Rule، S. (2007): Religiosity and quality of life in south Africa. Journal. of Social Indicators Research، 81، 417-434.

Sadoughi، M.، \& Salehi، Z. S. (2017). The relationship between anxiety، depression، and quality of life among women with breast cancer. International Journal of Academic research in Psychology، 4، 11-19.

Sarma، S.، \& Byrne، G. (2014). Relationship between anxiety and quality of life in older mental health patients. Australasian Journal on Aging، 33، 201-204.

Steger، M.، \& Frazier، P. (2005). Meaning in life: On link in the chain from religiousness to well-being. Journal of Counseling Psychology، 52، 574-582.

The WHOQOL Group. (1995). The World Health Organization quality of life assessment: Position Paper from the world health organization، Social Science and Medicine، 41، 1403-1409.

Turner، S. M. Stanly، M. A.، Beidel، D. C.، \& Bond، L.(1989). The social phobia and anxiety inventory: Construct validity. Journal of Psychopathology and Behavioral Assessment، 11، 221-134.

Witter، R. A.، Stock، W. A.، Okun` M. A.، \& Harring، M. J. (1985). Religious and subjective well-being in adult: A quantitative synthesis. Review of Religious research، 26، 332-342.

Ercan' H. (2017). The Relationship between Resilience and the Big Five Personality Traits in Emerging Adulthood. Eurasian Journal of Educational Research، 70، 83-103.

Shi، M. Liu‘ L.، Wang ‘ Z. Y.، \& Wang، L. (2015). The mediating role of resilience in the relationship between big five personality and anxiety among Chinese medical students: a cross-sectional study. PloS one، 10(3). 
Tamannaeifar، M.، \& Shahmirzaei، S. (2019). Prediction of Academic Resilience Based on Coping Styles and Personality Traits. Practice in Clinical Psychology، 7(1)، 1-10.

Lee، H. S.، Brown، S. L.، Mitchell، M. M. \& Schiraldi، G. R. (2008). Correlates of resilience in the face of adversity for Korean women immigrating to the US. Journal of Immigrant and Minority Health، 10(5)، 415-422.

Guinn، B.، Vincent، V.، \& Dugas، D. (2009). Stress and resilience among border Mexican American women. Hispanic Journal of Behavioral Sciences، 31(2)، 228-243.

Oshio، A.، Taku‘ K.، Hirano، M.، \& Saeed، G. (2018). Resilience and Big Five personality traits: A meta-analysis. Personality and Individual Differences‘ 127 ، 54-60.

Zhang، H.، Zhao، Q. Cao، P.، \& Ren، G. (2017). Resilience and quality of life: exploring the mediator role of social support in patients with breast cancer. Medical science monitor: international medical journal of experimental and clinical research، 23، 5969.

McCarthy، G.، Liston، A.، \& Adamis، D. (2017). Psychological resilience and quality of life amongst people with psychotic illnesses. European Psychiatry، 41 .https//doi.org/10.1016/j.eurpsy.2017.01.1605.

Yngve، A. (2016). Resilience against social anxiety: The role of social networks in social anxiety disorder. Linkopings Universitet: www.liu.se.

Ko، C. Y. A. \& \& Chang، Y. (2019). Investigating the relationships among resilience، social anxiety، and procrastination in a sample of college students. Psychological reports، 122(1)، 231-245.

Bonanno، G. A.، Ho، S. M.، Chan، J. C.، Kwong، R. S.، Cheung، C. K.، Wong، C. P.، \& Wong، V. C. (2008). Psychological resilience and dysfunction among hospitalized survivors of the SARS epidemic in Hong Kong: a latent class approach. Health Psychology، 27، 659-667. 
Volume (3) No. (4) 2020

Ovaska-Stafford، N.، Maltby، J، \& Dale، M. (2019). Literature Review: Psychological Resilience Factors in People with Neurodegenerative Diseases. Archives of Clinical Neuropsychology. https:/ doi.org/10.1039/arclin/aczo63. 
